Article

\title{
Design and Synthesis of Various 5'-Deoxy-5'-(4-Substituted-1,2,3-Triazol-1-yl)-Uridine Analogues as Inhibitors of Mycobacterium tuberculosis Mur Ligases
}

\author{
Vincent Hervin ${ }^{1}$, Ritu Arora ${ }^{2}$, Jyoti Rani ${ }^{2,3}$, Srinivasan Ramchandran ${ }^{3}$, Urmi Bajpai ${ }^{2}$, \\ Luigi A. Agrofoglio $1, *$ (i) and Vincent Roy $1, *$ (D) \\ 1 Institute of Organic and Analytical Chemistry, CNRS UMR 7311, Universite d'Orléans, Rue de Chartres, \\ CEDEX 2, 45067 Orleans, France; vincent.hervin@univ-orleans.fr \\ 2 Department of Biomedical Science, Acharya Narendra Dev College, University of Delhi, \\ New Delhi 110019, India; rituarora1391@gmail.com (R.A.); sharmajyoti829@gmail.com (J.R.); \\ urmibajpai@andc.du.ac.in (U.B.) \\ 3 G N Ramachandran Knowledge of Centre, Council of Scientific and Industrial Research-Institute of \\ Genomics and Integrative Biology (CSIR-IGIB), Room No. 130, Mathura Road, New Delhi 110025, India; \\ ramu@igib.res.in \\ * Correspondence: luigi.agrofoglio@univ-orleans.fr (L.A.A.); vincent.roy@univ-orleans.fr (V.R.); \\ Tel.: +33-(0)2-3849-4582 (L.A.A.); +33-(0)2-3849-4572 (V.R.)
}

Academic Editor: Jussara Amato

Received: 14 September 2020; Accepted: 19 October 2020; Published: 26 October 2020

\begin{abstract}
The synthesis of hitherto unknown 5'-deoxy-5'-(4-substituted-1,2,3-triazol-1-yl)-uridine and its evaluation, through an one-pot screening assay, against MurA-F enzymes involved in Mycobacterium tuberculosis (Mtb), are described. Starting from UDP- $N$-acetylmuramic acid (UDP-MurNAc), the natural substrate involved in the peptidoglycan biosynthesis, our strategy was to substitute the diphosphate group of UDP-MurNAc by a 1,2,3-triazolo spacer under copper-catalyzed azide-alkyne cycloaddition conditions. The structure-activity relationship was discussed and among the 23 novel compounds developed, $\mathrm{N}$-acetylglucosamine analogues 11c and 11e emerged as the best inhibitors against the Mtb MurA-F enzymes reconstruction pathway with an inhibitory effect of $56 \%$ and $50 \%$, respectively, at $100 \mu \mathrm{M}$. Both compounds are selective inhibitors of Mtb MurE, the molecular docking and molecular dynamic simulation suggesting that 11c and 11e are occupying the active site of Mtb MurE ligase.
\end{abstract}

Keywords: Mur ligase; nucleoside analogues; copper-catalyzed azide-alkyne cycloaddition; antibacterial agents; molecular modelling

\section{Introduction}

Mycobacterium tuberculosis (Mtb) disease is one of the top 10 causes of death worldwide and has developed multi-drug resistance [1]. The viability of $\mathrm{Mtb}$ is directly linked to its remarkable cell wall structure and especially the peptidoglycan layer. Mur ligases enable the development of cell walls through cytoplasmic and periplasmic biosynthesis [2,3]. Thus, cell wall biosynthesis and especially Mur ligases appear to be a relevant target for new antibiotics [4,5] especially since bacteria have developed different alarming resistance against antibiotics drugs [6-8]. Of interest, the amide ligases MurC, MurD, MurE and MurF share the same catalytic function with similar amino acid regions and preserve comparable structural properties that must be exploited for the design of multi-inhibition molecules, which can reduce the incidence of bacterial resistance [3,5,9]. As part of our drug discovery program, 
we aim to develop new sugar-nucleotides with structural diversity targeting Mtb Mur ligases using quick synthetic approaches; the key step of the proposed chemistry follows the synthetic ecofriendly 1,3-dipolar cycloaddition [10] such as described by Huisgen [11] and Sharpless [12]. The [1-3]-Triazole ring can be considered as a phosphate mimic which imparts stability compared to the diphosphate unit, and a linker as well. Herein, we report the synthesis and enzymatic inhibition evaluation of 5'-deoxy-5'-(4-substituted-1,2,3-triazol-1-yl) uridines as analogs of UDP-MurNAc, the natural substrate of all MurA-F enzymes involved in peptidoglycan biosynthesis, (Figure 1).

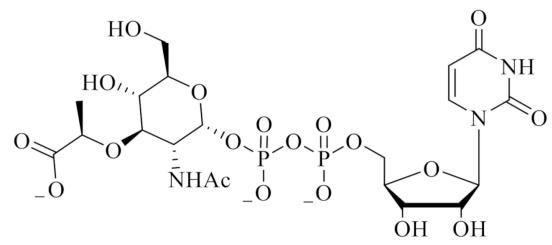

Figure 1. Structure of the natural substrate UDP-MurNAc.

\section{Results and Discussion}

\subsection{Chemistry}

5 -Azido-5'-deoxy-uridine 2 was obtained according to the literature $[13,14]$ on gram scale in $94 \%$ yield, through a one pot reaction, starting from commercially available uridine (1) in the presence of tetrabromomethane and triphenylphosphine through an in situ formation of $5^{\prime}$-bromo-5'-deoxy-uridine and subsequent substitution with sodium azide (Scheme 1). Azido analogue 2 was then reacted with a small library of alkyne derivatives bearing alcohols, amines, amides, carboxylic acids, aromatics and sugar moieties derivatives, chosen for their ability to form possible hydrogen bond interactions with the Mur ligase binding site and as a starting point in the development of Mur ligase inhibitors.

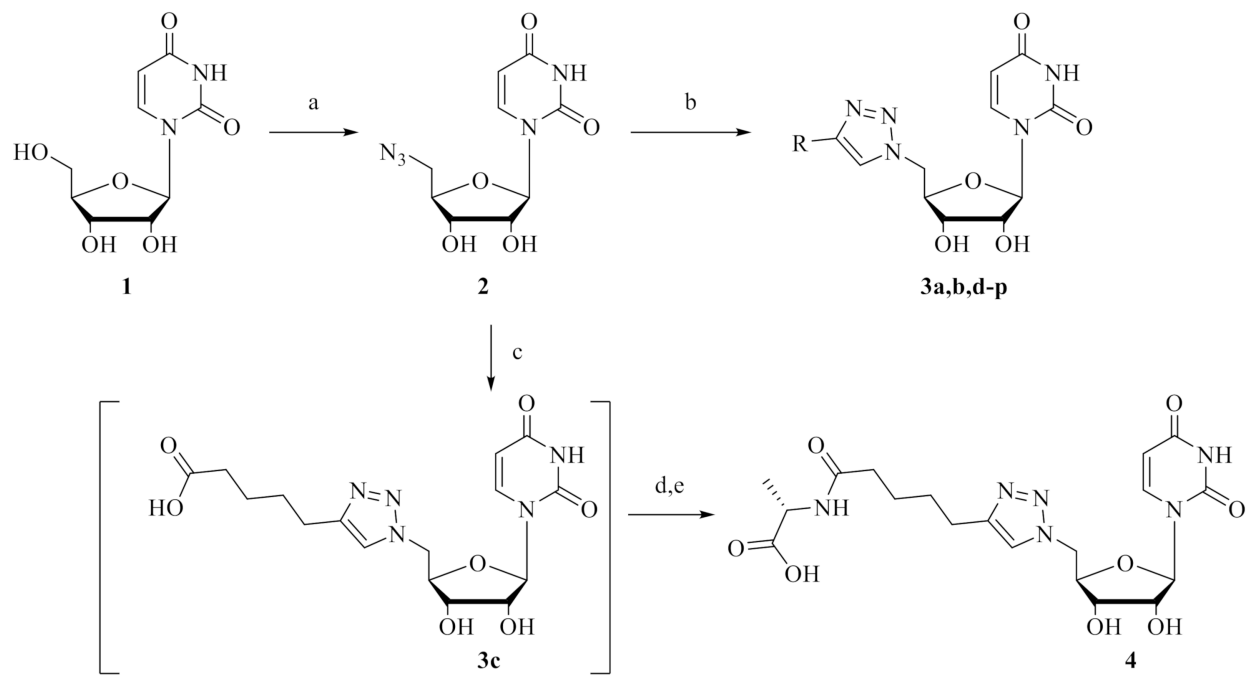

Scheme 1. Reagents and conditions. (a) $\mathrm{NaN}_{3}, \mathrm{Ph}_{3} \mathrm{P}, \mathrm{CBr}_{4}, \mathrm{DMF}, 25^{\circ} \mathrm{C}, 24 \mathrm{~h}, 94 \%$; (b) $\mathrm{CuSO}_{4} .5 \mathrm{H}_{2} \mathrm{O}$ $(10 \mathrm{~mol} \%)$, sodium ascorbate (0.6 eq), substituted alkynes, $t \mathrm{BuOH}: \mathrm{H}_{2} \mathrm{O}(2: 1), 40{ }^{\circ} \mathrm{C}, 35 \mathrm{~min}-19$ h, from $46 \%$ to $99 \%$; (c) $\mathrm{CuSO}_{4} \cdot 5 \mathrm{H}_{2} \mathrm{O}$, sodium ascorbate, 6-heptynoic acid, $t \mathrm{BuOH}: \mathrm{H}_{2} \mathrm{O}(2: 1)$, $40{ }^{\circ} \mathrm{C}$; (d) HOBt, BOP reagent, DIPEA, L-alanine methyl ester hydrochloride, dry DMF, $25{ }^{\circ} \mathrm{C}$, $16 \mathrm{~h}$; (e) $\mathrm{LiOH} . \mathrm{H}_{2} \mathrm{O}, \mathrm{THF}: \mathrm{H}_{2} \mathrm{O}(3: 1), 25{ }^{\circ} \mathrm{C}, 18 \mathrm{~h}$, then $\mathrm{H}^{+}, 29 \%$ from 2 (over 3 steps). where $\mathrm{R}$ is = (a) $\left(\mathrm{CH}_{2}\right)_{2} \mathrm{CO}_{2} \mathrm{H}$; (b) $\left(\mathrm{CH}_{2}\right)_{3} \mathrm{CO}_{2} \mathrm{H}$; (c) $\left(\mathrm{CH}_{2}\right)_{4} \mathrm{CO}_{2} \mathrm{H}$; (d) $\mathrm{CH}_{2} \mathrm{OH}$; (e) $\left(\mathrm{CH}_{2}\right)_{2} \mathrm{OH}$; (f) $\left(\mathrm{CH}_{2}\right)_{3} \mathrm{OH}$; (g) $\mathrm{CH}_{2} \mathrm{NH}_{2}$; (h) $\mathrm{CH}_{2} \mathrm{C}(\mathrm{O}) \mathrm{NH}_{2}$; (i) $\mathrm{CH}_{2} \mathrm{NH}\left(\mathrm{C}(\mathrm{O})\left(\mathrm{CH}_{2}\right)_{4} \mathrm{CH}_{3}\right.$; (j) $\mathrm{CH}_{2} \mathrm{NHC}(\mathrm{O})\left(\mathrm{CH}_{2}\right)_{6} \mathrm{CH}_{3}$; (k) $\left(\mathrm{m}, \mathrm{m}^{\prime}\right)-\left(\mathrm{CO}_{2} \mathrm{CH}_{3}\right)_{2} \mathrm{Ph}$; (l) (m,m')-( $\left.\mathrm{OCH}_{3}\right)_{2} \mathrm{Ph}$; (m) p- $\mathrm{NO}_{2}-\mathrm{Ph}$; (n) 2-pyrimidinyl; (o) 2-thiofuranyl; (p) $\mathrm{CH}_{2}-(1-\beta)-O-$ peracetylated glucose. 
The 1,3-dipolar cycloaddition between compound 2 and alkynes was performed in water/tert-butanol (1:2) solvent mixture at $40{ }^{\circ} \mathrm{C}$ with sodium ascorbate/CuSO 4 . Compounds 3a-p were isolated in yields ranging from $46 \%$ to $99 \%$, and ${ }^{1} \mathrm{H}$ - and ${ }^{13} \mathrm{C}-\mathrm{NMR}$ (HMBC) confirmed the regioselectivity of $(1,4)$-disubstituted [1-3]-triazole ring formation, without contamination by the (1,5)-regioisomer, (see Supplementary Materials).

Following the structure of the natural substrate UDP-MurNAc, we also synthesized the L-alanine peptidic derivative 4, rationally designed to interact at the natural substrate and amino acid pocket on the active site of Mtb Mur ligases. Peptidic analogue 4 was obtained from acidic derivative 3c in 29\% yield (three steps, from 2) using a peptide coupling reaction in the presence of hydroxybenzotriazole (HOBt) and benzotriazol-1-yloxytris (dimethylamino)phosphonium hexa- fluoro-phosphate (BOP) reagent followed by saponification and acidification.

We next investigated the biological influence of the $N$-acetylmuramic acid group on Mur ligase inhibition. The $\mathrm{N}$-acetylglucosamine moiety was thus connected to the $\mathrm{C} 5$ '-position of uridine through a CuAAc reaction, to replace the diphosphate group by the biologically stable [1-3]-triazolo spacer (Scheme 2). Starting from commercially available $N$-acetylglucosamine 5 , the anomeric position was substituted in the presence of propargylic alcohol and trimethylsilyl trifluoromethane-sulfonate (TMSOTf) to give the alkyne derivative 6 in 52\% yield. CuAAC reaction between 5-azidouridine 2 and 6 give the desired $N$-acetylglucosamine uridine 7 in 59\% yield. We also examined the influence of the C6-subtituted $N$-acetyl glucosamine derivatives 11a-e on the inhibition activity. Tosylation of the primary alcohol at the C6-position of $\mathbf{6}$ in the presence of tosyl chloride and pyridine give the intermediate 8 , which was converted through CuAAC reaction in the presence of $5^{\prime}$-azido-5'-deoxyuridine 2 to the corresponding glucosamine-uridine intermediate 9 . Nucleophilic substitution of the tosyl group with sodium azide produced the intermediate $\mathbf{1 0}$ in moderate $64 \%$ yield. Intermediate 10 was then subjected to $\mathrm{CuAAc}$ reactions with various alkynes derivatives chosen for their abilities to generate hydrogen bonds and final derivatives 11a-e were obtained in yields ranging from $19 \%$ to $90 \%$.

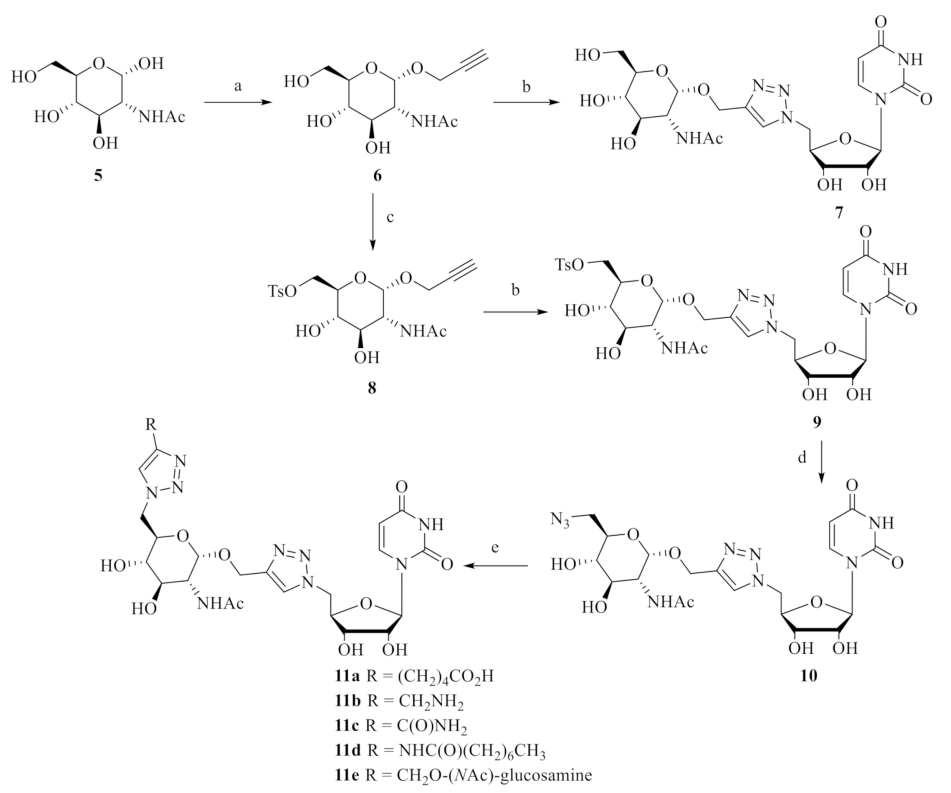

Scheme 2. Reagents and conditions: (a) TMSOTf, propargyl alcohol, $4 \AA \mathrm{MS}, 80{ }^{\circ} \mathrm{C}, 3 \mathrm{~h}, 52 \%$; (b) $\mathrm{CuSO}_{4} \cdot 5 \mathrm{H}_{2} \mathrm{O}$, sodium ascorbate, compound 2, $\mathrm{tBuOH}: \mathrm{H}_{2} \mathrm{O}(2: 1), 40{ }^{\circ} \mathrm{C}, 59 \%$ (7) and $82 \%$ (9) (c) $\mathrm{TsCl}$, dry pyridine, $25^{\circ} \mathrm{C}, 16 \mathrm{~h}, 50 \%$; (d) $\mathrm{NaN}_{3}$, dry DMF, $25^{\circ} \mathrm{C}, 72 \mathrm{~h}, 64 \%$; (e) $\mathrm{CuSO}_{4} \cdot 5 \mathrm{H}_{2} \mathrm{O}$, sodium ascorbate, substituted alkynes, $t \mathrm{BuOH}: \mathrm{H}_{2} \mathrm{O}(2: 1), 40{ }^{\circ} \mathrm{C}, 19-90 \%$.

All synthesized compounds were fully characterized and evaluated for their biological activity against Mycobacterium tuberculosis MurA-F enzymes. 


\subsection{In Vitro Mur Ligase Inhibition Activity}

Firstly, we evaluated the inhibitory activity of the synthesized $5^{\prime}$-deoxy-5'-(4-substituted1,2,3-triazol-1-yl) uridines against Mycobacterium tuberculosis (Mtb) MurA-F enzymes in vitro, through our recently published [15] "one-pot assay" in order to screen and identify molecules with potential biological activity against a pool of Mtb MurA-F enzymes. The result from this in vitro screening are reported in Table 1 for compounds 3a-p, 4 with 4-substituted-1,2,3-triazole moiety bearing an alkyl chain with terminal carboxylic acid $\mathbf{3 a} \mathbf{a}-\mathbf{c}$, alcohol $\mathbf{3 d} \mathbf{d}-\mathbf{f}$, amine/amide $\mathbf{3 h}-\mathbf{k}$ functional groups, peptidic 4, which could afford hydrogen bond with the active site of Mtb Mur ligases. The results from Table 1 show that with an increased distance between the carboxylic acid and triazole ring (compounds $\mathbf{3 a}-\mathbf{c}$ ), the inhibition increased from 11 to $29 \%$, but conversely, the inhibitory activity of alcoholic compounds $\mathbf{3 d}-\mathbf{f}$ decreased from 19 to $14 \%$ with the alkyl chain length. Further substitution by amine $\mathbf{3 g}$, amide $\mathbf{3 h}$ and amide-triazolyl bearing hydrophobic alkyl chains $3 \mathbf{i}-\mathbf{j}$ did not show improved inhibitory effects (39\%). Both aromatic substitutions 3k-o, with increased lipophilicity, electron withdrawing (ester-, nitro-) or donating (methoxy-) effect or a pyridine ring, did not display inhibitory activity exceeding $25 \%$. Additionally, substitutions of the triazolo moiety by percylated glucose $3 \mathbf{p}$ and L-alanine peptidic moiety 4 also did not exhibit better inhibition activity with $30 \%$ and $21 \%$ respectively.

Table 1. Results of the inhibition of one-pot assay containing Mtb MurA-F enzymes by compounds $3 a-p$ and 4 at $100 \mu \mathrm{M}$.

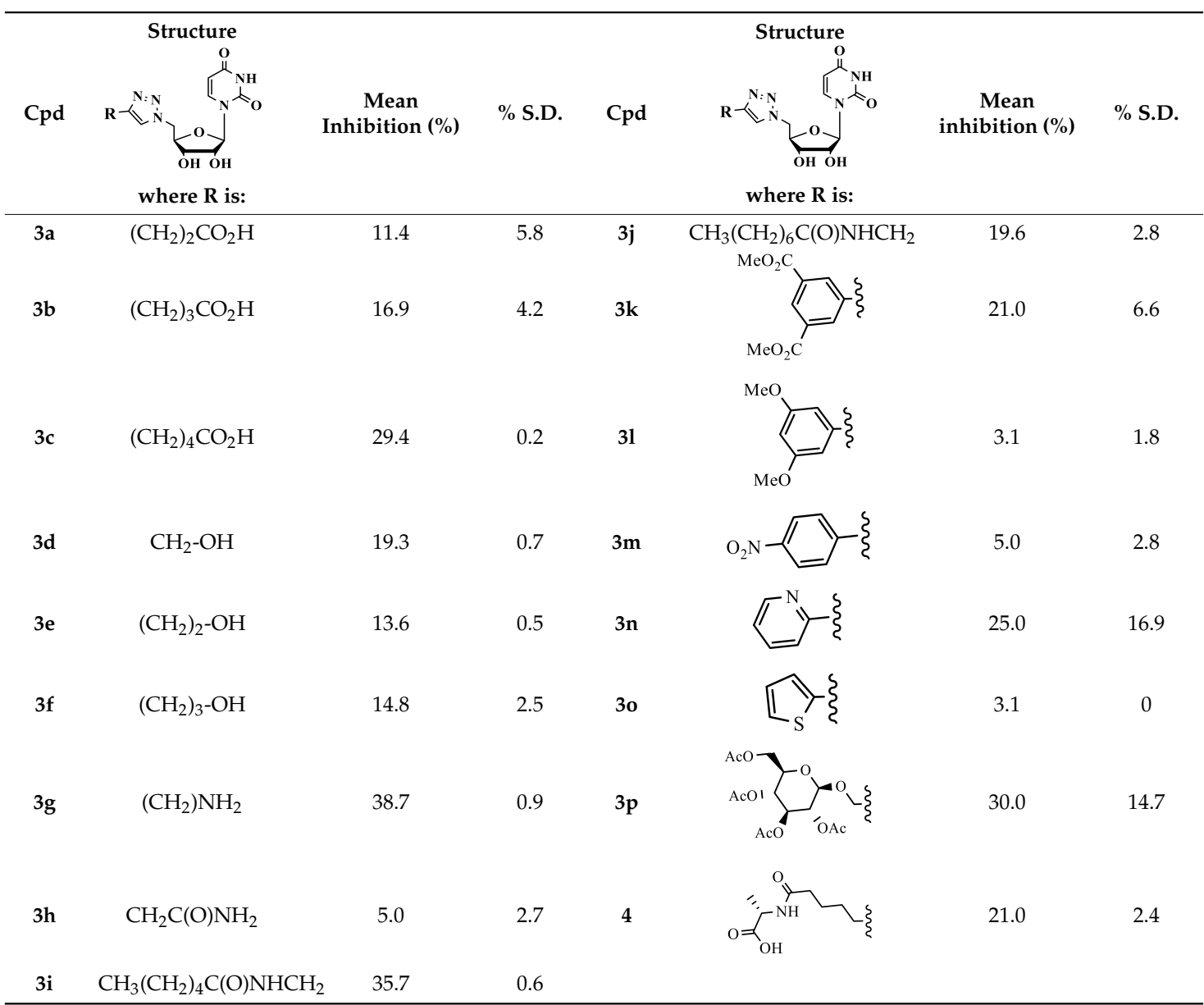

The second series of molecules bearing glucosamine derivatives 7, 11a-e were also tested, respectively, for their inhibitory effect against the one-pot assay (Table 2). Compared with the scaffold 7, we found substitution by triazole derivatives at C6-position of glucosamine 11a-e to increase the inhibitory activity. Substitution by carboxylic acid 11a or amino group $11 \mathbf{b}$ showed a moderate $25-30 \%$ 
of inhibition. The inhibitory effect could be improved up to $56 \%$ for the amide derivative group 11c or glucosamine 11e (50\%). This effect could be due to suitable H-bonding between 11c,e and the enzyme catalytic site.

Table 2. Results of the inhibition of one-pot assay containing Mtb MurA-F enzymes by glucosamine derivatives 7 and 11a-e at $100 \mu \mathrm{M}$.

inhibition (\%)

Secondly, in order to define and elucidate the binding modes and specific inhibitory activities of the only compounds which exhibited $\geq 50 \%$ inhibition of one-pot assay containing Mtb MurA-F enzymes, we evaluated the abilities of 11c and 11e, respectively, to inhibit each of Mtb MurC-F ligases, taken separately, at $100 \mu \mathrm{M}$ (Table 3).

Table 3. Inhibitory effect of compound 11c and 11e $(100 \mu \mathrm{M})$ on Mtb MurC-F ligases.

\begin{tabular}{cccc}
\hline Targets & Cpd & Mean Inhibition (\%) & \% S.D. \\
\hline \multirow{2}{*}{ MurC } & 11c & 12.1 & 1.52 \\
& 11e & 1.0 & 0.89 \\
MurD & 11c & 23.0 & 1.11 \\
& 11e & 5.2 & 1.25 \\
MurE & 11c & 41.8 & 1.42 \\
& 11e & 48.9 & 3.41 \\
MurF & 11c & 6.1 & 1.94 \\
& 11e & 12.5 & 4.59 \\
\hline
\end{tabular}

Based on the individual assay analysis against Mur C, MurD, MurE and MurF enzymes compounds 11c and 11e were found to inhibit MurE enzyme selectively (Table 3). Also, since out of the four Mtb Mur ligases, the crystal structure of MurE has been solved [16], we did a computational analysis (molecular docking and molecular dynamic simulation) to investigate the stability of interaction between Mtb MurE and the compounds 11c and 11e. 


\subsection{Molecular Docking}

Molecular docking of compounds 11c and 11e, respectively, with Mtb MurE showed a docking score of $-9.9 \mathrm{kcal} / \mathrm{mol}$, which is well below the chosen cut-off of $-9.0 \mathrm{kcal} / \mathrm{mol}$ docking score with the natural ligand for Mtb MurE.

Once the selected compounds were docked and filtered on the basis of binding affinity, they were visualized using Pymol [17], for the identification of binding residues. The binding pocket of MurE contains the following amino acid residues: LEU67, ARG68, ALA69, GLN70, LYS157, ARG230, HIS248, SER222, THR195, and LEU194. Compound 11c with binding affinity $-9.9 \mathrm{kcal} / \mathrm{mol}$ formed hydrogen bonds with THR154, SER155, ARG377, TYR397, GLY502, THR180, THR195, HIS395, ARG230, ASN449, ASP448, and HIS248 amino acid residues (Figure 2A). Compound 11e with same binding affinity $(-9.9 \mathrm{kcal} / \mathrm{mol})$ formed hydrogen bonds to the ARG230, SER222, THR196, ASP247, ASN243, SER155, GLY156, THR180, GLY156, ARG377, SER402 residues of Mtb MurE (Figure 2B). This visual rescoring of the docked complex revealed the possession of compounds in the binding pocket of the protein. The stability of their binding tendency was further confirmed by using molecular dynamic simulation technique.

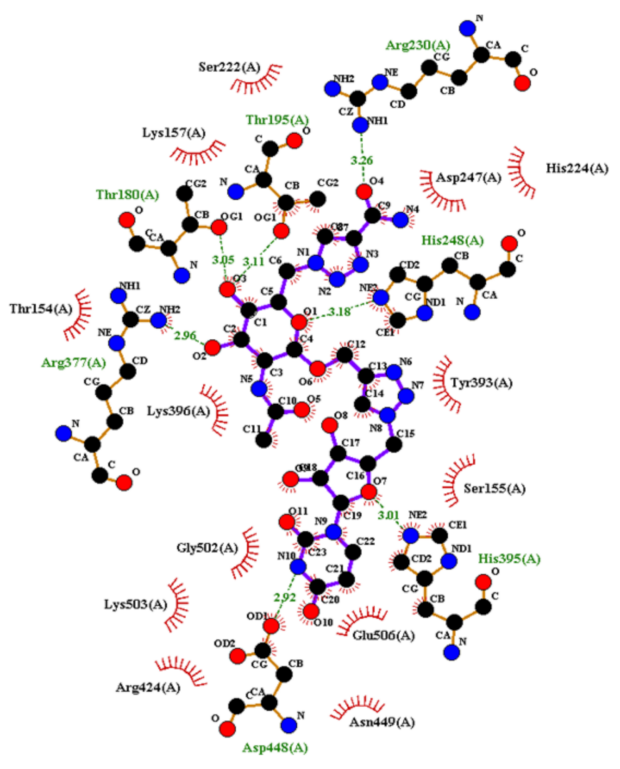

(A)

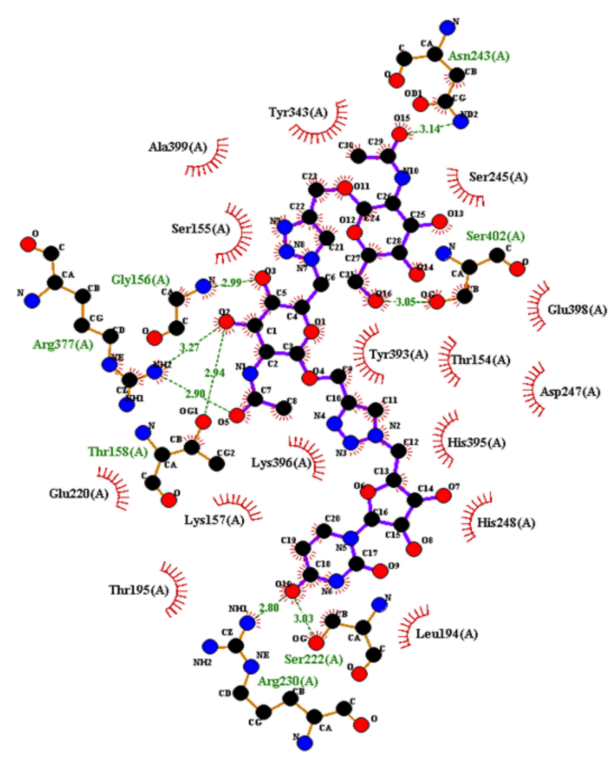

(B)

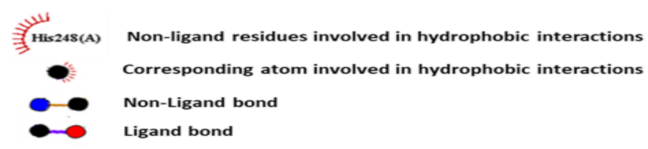

Figure 2. Hydrogen bonds and hydrophobic interactions between Mtb MurE and 11c (A) and 11e (B), respectively. The green dotted lines depict the hydrogen bonds whereas the other residues represent the hydrophobic interactions with the respective compounds.

\subsection{Molecular Dynamic Simulation}

Further, stability of the Mtb MurE-compound complexes was examined by MD simulation. MD simulation was carried out for $40 \mathrm{~ns}$ and the stability of the complexes was analyzed by calculating RMSD and the residual fluctuation in the protein was measured by evaluating the RMSF. The RMSD values for the complex were compared with the native protein in order to find whether the ligand remains bound or drifts away from the active site. We obtained lower RMSD values for both 11c and 11e (Figure 3A,B), thus suggesting the compounds to have occupied the active site of Mtb MurE throughout the simulation. While terminals of the protein showed higher fluctuations after docking with the compound 11c with compound 11e, protein residues exhibited less fluctuation (Figure 3C,D). 
For both the compounds, the binding site residues did not show much fluctuation throughout the simulation. On examining the hydrogen bond pattern (Figure 3E,F), stable hydrogen bonding was noted between the compounds 11c and 11e with the active site residues of Mtb MurE.

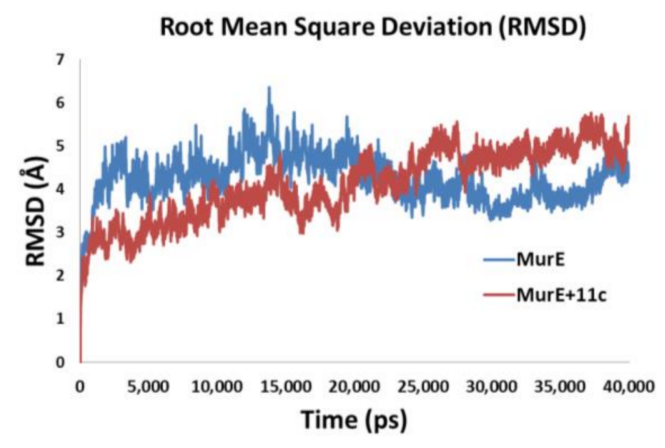

(A)

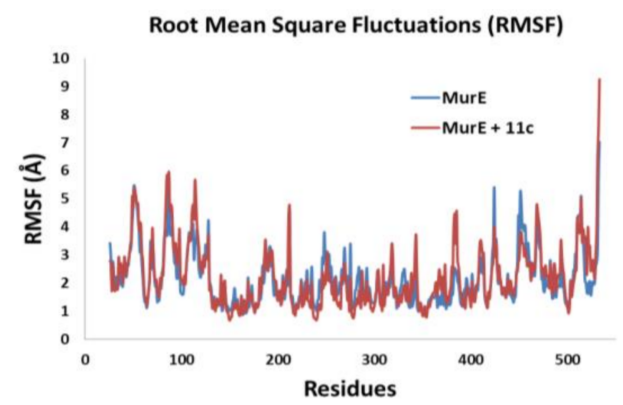

(C)

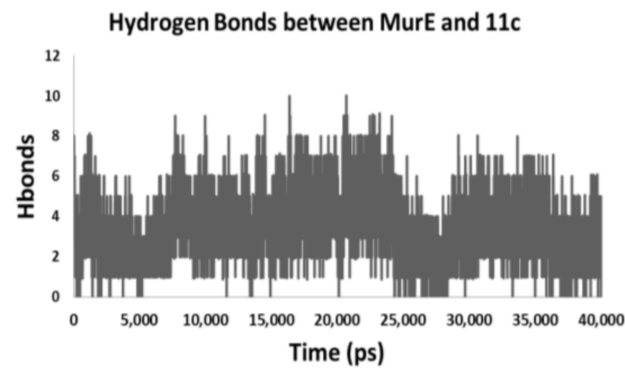

(E)

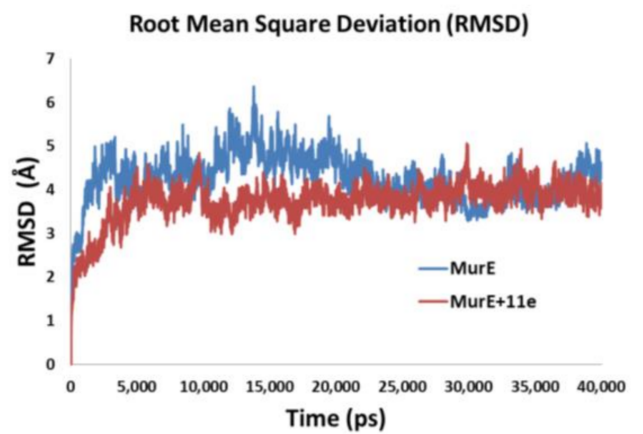

(B)

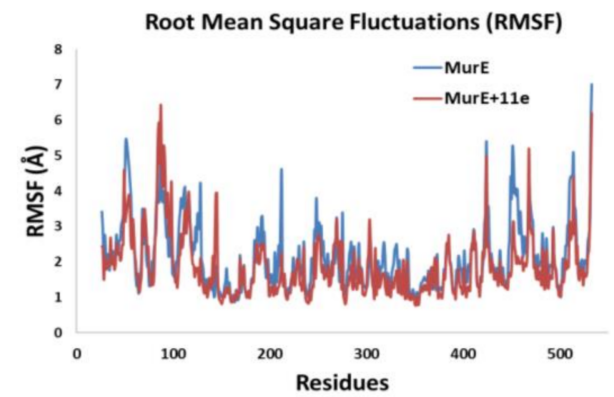

(D)

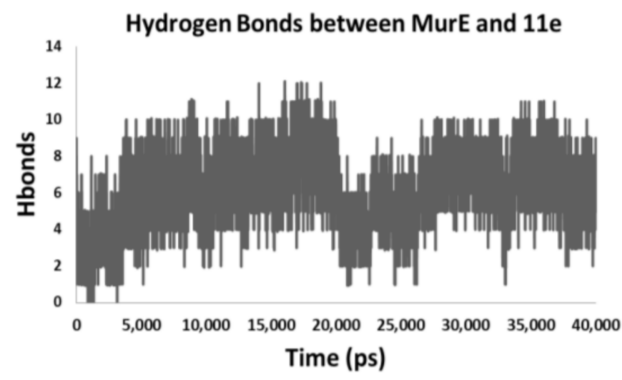

(F)

Figure 3. Molecular dynamic simulation plots of compounds 11c and 11e, respectively, with Mtb MurE:

(A) and (B): RMSD plots; (C) and (D): RMSF plots; (E) and (F): hydrogen bonds.

\section{Materials and Methods}

\subsection{General Information}

Commercially available chemicals were provided as reagent grade and used as received. Some reactions requiring anhydrous conditions were carried out using oven-dried glassware and under an atmosphere of dry argon. All anhydrous solvents were provided from commercially sources as very dry reagents. The reactions were monitored by thin layer chromatography (TLC) analysis using silica gel precoated plates (Kieselgel 60F254, E. Merck, Darmstadt, Germany). Compounds were visualized by UV irradiation (Sigma Aldrich Chimie, St-Quentin-Fallavier, France) and/or spraying with sulfuric acid $\left(\mathrm{H}_{2} \mathrm{SO}_{4} 5 \%\right.$ in ethanol) stain followed by charring at average $150{ }^{\circ} \mathrm{C}$. Flash column chromatography was performed on Silica Gel 60 M (0.040-0.063 mm, E. Merck, Darmstadt, Germany. The infrared spectra were measured with a Thermo Fischer Nicolet iS 10 FTIR spectrometer (Illkirch, France). The ${ }^{1} \mathrm{H}$ and ${ }^{13} \mathrm{C}$-NMR spectra were recorded on an Bruker Avance DPX 250 or Avance 
400 spectrometer (Champs sur Marne, France). Chemical shifts are given in ppm and are referenced to the deuterated solvent signal or to TMS as internal standard and multiplicities are reported as $\mathrm{s}$ (singlet), d (doublet), $\mathrm{t}$ (triplet), $\mathrm{q}$ (quartet) and $\mathrm{m}$ (multiplet). Carbon multiplicities were assigned by distortion less enhancement by polarization transfer (DEPT) experiments. ${ }^{1} \mathrm{H}$ and ${ }^{13} \mathrm{C}$ signals were attributed on the basis of $\mathrm{H}-\mathrm{H}$ and $\mathrm{H}-\mathrm{C}$ correlations. High Resolution Mass spectra were performed on a Bruker Q-TOF MaXis spectrometer by the "Fédération de Recherche" ICOA/CBM (FR2708) platform. LC-MS data was acquired on a Thermo-Fisher UHPLC-MSQ system (Illkirch, France) equipped with an electron spray ionization source (ESI). The temperature of the source was maintained at $350{ }^{\circ} \mathrm{C}$. Initially, the cone voltage was set at $35 \mathrm{~V}$ and after 5 min was increased to $75 \mathrm{~V}$. In full scan mode, data was acquired between 100 and $1000 \mathrm{~m} / \mathrm{z}$ in the positive mode with a $1.00 \mathrm{~s}$ scan time. In addition, a UV detection was performed with a Diode array detector at three wavelengths 273, 254 and $290 \mathrm{~nm}$, respectively. A water/methanol (70\%/30\%) solution mixture with $0.1 \%$ formic acid was used as mobile phase. The composition of the mobile phase was increased to $100 \%$ methanol with $0.1 \%$ formic acid with a $7 \%$ ramp. The flow rate was set at $0.300 \mathrm{~mL} \mathrm{~min}^{-1}$. Samples diluted in the mobile phase were injected $(3 \mu \mathrm{L})$ on a C18 column (X-terra, Waters, Guyancourt, France), $2.1 \mathrm{~mm}$ internal diameter, and $100 \mathrm{~mm}$ length placed into an oven at $40{ }^{\circ} \mathrm{C}$. Electronic extraction of ions was performed and the subsequent areas under the corresponding chromatographic peaks determined.

\subsection{Synthesis}

3.2.1. Preparation of 1-((2R,3R,4S,5R)-5-(azidomethyl)-3,4-dihydroxytetrahydrofuran-2-yl)-pyrimidine2,4-(1H,3H)-dione (2; CAS: 39483-48-2)

To a flame-dried round-bottom flask, tetrabromomethane (10.2 g, $30.8 \mathrm{mmol}, 1.5 \mathrm{eq})$ was added to a solution of uridine 1 (5.0 g, $20.5 \mathrm{mmol}, 1.0 \mathrm{eq})$, triphenylphosphine (7.68 g, $29.3 \mathrm{~mol}, 1.43 \mathrm{eq})$ and sodium azide $(4.0 \mathrm{~g}, 61.5 \mathrm{mmol}, 3.0 \mathrm{eq})$ with dry DMF $(50 \mathrm{~mL})$ at $25{ }^{\circ} \mathrm{C}$ under argon atmosphere. Then, the solution was stirred for $24 \mathrm{~h}$. The reaction mixture became a slightly yellow pale solution. This was stopped and concentrated to dryness in vacuo. The resulting residue was purified by flash chromatography (DCM/MeOH 9/1) to give a white solid (5.20 g, 94\%). Rf (DCM/MeOH 9:1) =0.33. ${ }^{1} \mathrm{H}-\mathrm{NMR}\left(400 \mathrm{MHz},\left(\mathrm{CD}_{3}\right)_{2} \mathrm{CO}\right) \delta(\mathrm{ppm}): 10.0(1 \mathrm{H}, \mathrm{s}, \mathrm{N}-\mathrm{H}) ; 7.66(1 \mathrm{H}, \mathrm{d}, J=8.09 \mathrm{~Hz},=\mathrm{CH}) ; 5.86(1 \mathrm{H}$, $\mathrm{d}, J=4.43 \mathrm{~Hz}, \mathrm{CH}) ; 5.62(1 \mathrm{H}, \mathrm{d}, J=8.09 \mathrm{~Hz},=\mathrm{CH}) ; 4.73(1 \mathrm{H}, \mathrm{m}, \mathrm{CH}) ; 4.45(1 \mathrm{H}, \mathrm{m}, \mathrm{CH}) ; 4.32(1 \mathrm{H}, \mathrm{m}$, $\mathrm{CH}) ; 4.18(1 \mathrm{H}, \mathrm{m}, \mathrm{CH}) ; 4.04(1 \mathrm{H}, \mathrm{m}, \mathrm{CH}) ; 3.60-3.72\left(2 \mathrm{H}, \mathrm{m}, \mathrm{CH}_{2}\right) .{ }^{13} \mathrm{C}-\mathrm{NMR}\left(100 \mathrm{MHz},\left(\mathrm{CD}_{3}\right)_{2} \mathrm{CO}\right)$ $\delta(\mathrm{ppm}): 162.5(\mathrm{C}=\mathrm{O}) ; 150.5(\mathrm{C}=\mathrm{O}) ; 140.7 ; 102.1 ; 90.2 ; 82.4 ; 73.4 ; 70.7 ;$ 52.0. ESI-HRMS calculated for $\left[\mathrm{C}_{9} \mathrm{H}_{12} \mathrm{~N}_{5} \mathrm{O}_{5}\right]^{+} m / z 270.0832$ and found $m / z$ 270.0832. IR (neat, $\mathrm{cm}^{-1}$ ): 3368.4br;3100.2m;3060.1 $m ; 2101.6 \mathrm{~s}$; $1662.9 \mathrm{~s} ; 1463.2 \mathrm{~m} ; 1385.7 \mathrm{~m} ; 1264.7 \mathrm{~m} ; 1100.2 \mathrm{~m} ; 1034.2 \mathrm{~m} ; 811.5 w ; 764.4 w .[\alpha]_{\mathrm{D}}{ }^{20}=+27.4(\mathrm{C}=0.02 \mathrm{M}$, $\mathrm{MeOH})$. LC-MS purity $98.9 \%, \mathrm{t}_{\mathrm{R}}=3.51 \mathrm{~min}$ water/methanol (70:30 $\mathrm{vol} / \mathrm{vol}, 0.1 \%$ of formic acid).

\subsubsection{General Procedure: CuAAc Reaction}

To a solution of $5^{\prime}$-azidouridine $2(1.0 \mathrm{eq})$ in $t$ - $\mathrm{BuOH}: \mathrm{H}_{2} \mathrm{O}(2: 1)(10 \mathrm{~mL} / 0.5 \mathrm{mmol})$, the corresponding alkyne (1.0 eq), copper sulfate pentahydrate $(10 \mathrm{~mol} \%)$ and (+)-sodium ascorbate $(0.6 \mathrm{eq})$ were added sequentially. Then the reaction mixture was stirred at $40^{\circ} \mathrm{C}$ and monitored by TLC. When the starting material was completely converted, the reaction was stopped and co-evaporated twice with $\mathrm{MeOH}$ $(20 \mathrm{~mL} / 0.5 \mathrm{mmol})$. The residue was purified by flash chromatography $\left(\mathrm{H}_{2} \mathrm{O} /{ }^{\mathrm{I}} \mathrm{PrOH} / \mathrm{EtOAc} 1 / 6 / 3\right.$ or $\mathrm{DCM} / \mathrm{MeOH}$ 9/1) and then the residue was co-evaporated several times with $\mathrm{MeOH}(x \times 15 \mathrm{~mL})$ to remove residual water. Next, a second flash chromatography purification (acetone/MeOH 9/1 or EtOAc/MeOH 9/1) was used to give a pure product. All analysis are described according to each alkyne used.

3-(1-(((2R,3S,4R,5R)-5-(2,4-Dioxo-3,4-dihydropyrimidin-1(2H)-yl)-3,4-dihydroxytetrahydrofuran-2-yl)-methyl) -1H-1,2,3-triazol-4-yl)propanoic acid (3a). According to the general procedure, copper (II) sulfate pentahydrate $(6 \mathrm{mg}, 0.02 \mathrm{mmol}, 10 \mathrm{~mol} \%$ ) and sodium ascorbate ( $28 \mathrm{mg}, 0.14 \mathrm{mmol}, 0.6$ eq) were added to a solution of 5'-azido-5'-deoxyuridine 2 (65 mg, $0.24 \mathrm{mmol}, 1.0 \mathrm{eq})$ and 4-pentynoic acid 
(24 mg, $0.24 \mathrm{mmol}, 1.0 \mathrm{eq}$ ) with $t \mathrm{BuOH}: \mathrm{H}_{2} \mathrm{O}(4 \mathrm{~mL})$. The reaction mixture was stirred for $2.5 \mathrm{~h}$ at $40{ }^{\circ} \mathrm{C}$. The residue was purified by a flash chromatography $\left(\mathrm{H}_{2} \mathrm{O} / \mathrm{i} \mathrm{PrOH} / \mathrm{EtOAc} 1: 6: 3\right)$ followed by a second flash chromatography (acetone/ $\mathrm{MeOH} 9 / 1$ ) to give the desired product as white solid (50 mg, 56\%). Rf $\left(\mathrm{H}_{2} \mathrm{O} /{ }^{\mathrm{i}} \mathrm{PrOH} / \mathrm{EtOAc} 1: 6: 3\right)=0.30 .{ }^{1} \mathrm{H}-\mathrm{NMR}\left(400 \mathrm{MHz}, \mathrm{DMSO}-\mathrm{d}_{6}\right) \delta(\mathrm{ppm}): 11.37(1 \mathrm{H}, \mathrm{s}$, $N-\mathrm{H}) ; 7.81\left(1 \mathrm{H}, \mathrm{s},=\mathrm{CH}_{\text {triazol }}\right) ; 7.49(1 \mathrm{H}, \mathrm{d}, J=7.95 \mathrm{~Hz},=\mathrm{CH}) ; 5.74(1 \mathrm{H}, \mathrm{d}, J=5.03 \mathrm{~Hz}, \mathrm{CH}) ; 5.63$ $(1 \mathrm{H}, \mathrm{d}, J=7.95 \mathrm{~Hz}, \mathrm{CH}) ; 4.56-4.68\left(2 \mathrm{H}, \mathrm{m}, \mathrm{CH}_{2}\right) ; 4.12(1 \mathrm{H}, \mathrm{m}, \mathrm{CH}) ; 4.01(1 \mathrm{H}, \mathrm{m}, \mathrm{CH}) ; 3.94(1 \mathrm{H}, \mathrm{m}$, $\mathrm{CH}) ; 2.82\left(2 \mathrm{H}, \mathrm{t}, J=7.79 \mathrm{~Hz}, \mathrm{CH}_{2}\right), 2.52\left(2 \mathrm{H}, \mathrm{t}, J=7.72 \mathrm{~Hz}, \mathrm{CH}_{2}\right) .{ }^{13} \mathrm{C}-\mathrm{NMR}(100 \mathrm{MHz}$, DMSO-d 6$) \delta$ (ppm): 174.5; 163.5; 151.1; 146.6; 141.5; 123.2; 102.5, 89.1; 82.2; 72.6; 71.0; 51.5; 34.3; 21.4. ESI-HRMS calculated for $\left[\mathrm{C}_{14} \mathrm{H}_{18} \mathrm{~N}_{5} \mathrm{O}_{7}\right]^{+} \mathrm{m} / z 368.1200$ and found $\mathrm{m} / \mathrm{z} 368.1201$. IR (neat, $\mathrm{cm}^{-1}$ ): $3201.0 b r ; 2928.7 m$; $1682.4 s ; 1462.7 w ; 1384.5 m ; 1261.4 m ; 1100.6 m ; 1056.1 m ; 813.1 w .[\alpha]_{\mathrm{D}}{ }^{20}=+32.7(\mathrm{C}=0.017 \mathrm{M}, \mathrm{MeOH})$. LC-MS purity $97.2 \%, t_{R}=3.23 \mathrm{~min}$ water/methanol (70:30 vol/vol, $0.1 \%$ of formic acid).

4-(1-(((2R,3S,4R,5R)-5-(2,4-Dioxo-3,4-dihydropyrimidin-1(2H)-yl)-3,4-dihydroxytetrahydrofuran-2-yl)-methyl) -1H-1,2,3-triazol-4-yl)butanoic acid (3b). According to the general procedure, copper(II) sulfate pentahydrate ( $6 \mathrm{mg}, 0.02 \mathrm{mmol}, 10 \mathrm{~mol} \%$ ) and sodium ascorbate $(28 \mathrm{mg}, 0.14 \mathrm{mmol}, 0.6 \mathrm{eq})$ were added to a solution of $5^{\prime}$-azido-5'-deoxyuridine $2(65 \mathrm{mg}, 0.24 \mathrm{mmol}, 1.0 \mathrm{eq})$ and 5-hexynoic acid $\left(27 \mathrm{mg}, 0.24 \mathrm{mmol}, 1.0 \mathrm{eq}\right.$ ) with $\mathrm{tBuOH}: \mathrm{H}_{2} \mathrm{O}(4 \mathrm{~mL})$. The reaction mixture was stirred for $2.5 \mathrm{~h}$ at $40^{\circ} \mathrm{C}$. The residue was purified by a flash chromatography $\left(\mathrm{H}_{2} \mathrm{O} / \mathrm{PrOH} / \mathrm{EtOAc} 1: 6: 3\right)$ followed by a second flash chromatography (acetone/ $\mathrm{MeOH} 9 / 1$ ) to give the desired product as white solid (55 $\mathrm{mg}, 60 \%$ ). $\operatorname{Rf}\left(\mathrm{H}_{2} \mathrm{O} / \mathrm{PrOH} / \mathrm{EtOAc} 1: 6: 3\right)=0.41 .{ }^{1} \mathrm{H}-\mathrm{NMR}\left(400 \mathrm{MHz}, \mathrm{DMSO}-\mathrm{d}_{6}\right) \delta(\mathrm{ppm}): 11.38(1 \mathrm{H}, \mathrm{s}, N-\mathrm{H}) ; 7.85$ $\left(1 \mathrm{H}, \mathrm{s},=\mathrm{CH}_{\text {triazol }}\right) ; 7.50(1 \mathrm{H}, \mathrm{d}, J=7.80 \mathrm{~Hz},=\mathrm{CH}) ; 5.74(1 \mathrm{H}, \mathrm{d}, J=5.66 \mathrm{~Hz}, \mathrm{CH}) ; 5.63(1 \mathrm{H}, \mathrm{d}, J=7.80 \mathrm{~Hz}$, $=\mathrm{CH}) ; 4.63\left(2 \mathrm{H}, \mathrm{m}, \mathrm{CH}_{2}\right) ; 4.13(1 \mathrm{H}, \mathrm{m}, \mathrm{CH}) ; 4.03(1 \mathrm{H}, \mathrm{t}, J=5.37 \mathrm{~Hz}, \mathrm{CH}) ; 3.96(1 \mathrm{H}, \mathrm{t}, J=4.78 \mathrm{~Hz}, \mathrm{CH})$; $2.62\left(2 \mathrm{H}, \mathrm{t}, J=7.53 \mathrm{~Hz}, \mathrm{CH}_{2}\right), 2.25\left(2 \mathrm{H}, \mathrm{t}, J=7.37 \mathrm{~Hz}, \mathrm{CH}_{2}\right) 1.80\left(2 \mathrm{H}, \mathrm{q}, J=7.58 \mathrm{~Hz}, \mathrm{CH}_{2}\right) .{ }^{13} \mathrm{C}-\mathrm{NMR}$ $(100 \mathrm{MHz}$ DMSO-d 6 ) $\delta$ (ppm): 174.8; 163.4; 151.1; 146.9; 141.5; 123.2; 102.5, 89.1; 82.2; 72.5; 71.0; $51.5 ; 33.7 ; 24.9 ; 24.8$. ESI-HRMS calculated for $\left[\mathrm{C}_{15} \mathrm{H}_{20} \mathrm{~N}_{5} \mathrm{O}_{7}\right]^{+} \mathrm{m} / z 382.1357$ and found $m / z 382.1356$. IR (neat, $\mathrm{cm}^{-1}$ ): $3139.1 \mathrm{br} ; 2925.2 \mathrm{~m} ; 1682.3 \mathrm{~s} ; 1462.2 w ; 1385.6 \mathrm{~m} ; 1261.9 \mathrm{~m} ; 1223.7 \mathrm{~m} ; 1100.5 \mathrm{~m} ; 1055.7 \mathrm{~m}$; 812.8w. $[\alpha]_{\mathrm{D}}{ }^{20}=+86.0(\mathrm{C}=0.025 \mathrm{M}, \mathrm{MeOH})$. LC-MS purity $95.5 \%, \mathrm{t}_{\mathrm{R}}=3.87 \mathrm{~min}$ water $/ \mathrm{methanol}$ (70:30 vol/vol, $0.1 \%$ of formic acid).

5-(1-(((2R,3S,4R,5R)-5-(2,4-Dioxo-3,4-dihydropyrimidin-1(2H)-yl)-3,4-dihydroxytetrahydrofuran-2-yl)-methyl) -1H-1,2,3-triazol-4-yl)pentanoic acid (3c). According to the general procedure, copper(II) sulfate pentahydrate $(6 \mathrm{mg}, 0.02 \mathrm{mmol}, 10 \mathrm{~mol} \%)$ and sodium ascorbate $(28 \mathrm{mg}, 0.14 \mathrm{mmol}, 0.6 \mathrm{eq})$ were added to a solution of $5^{\prime}$-azido-5'-deoxyuridine $2(65 \mathrm{mg}, 0.24 \mathrm{mmol}, 1.0 \mathrm{eq})$ and 6-heptynoic acid (34 mg, $0.24 \mathrm{mmol}, 1.0 \mathrm{eq}$ ) with $t \mathrm{BuOH}: \mathrm{H}_{2} \mathrm{O}(4 \mathrm{~mL})$. The reaction mixture was stirred for $1 \mathrm{~h}$ at $40^{\circ} \mathrm{C}$. The residue was purified by a flash chromatography $\left(\mathrm{H}_{2} \mathrm{O} / \mathrm{PrOH} / \mathrm{EtOAc} 1: 6: 3\right)$ followed by a second flash chromatography (acetone/ $\mathrm{MeOH} 9 / 1)$ to give the desired product as white solid $(60 \mathrm{mg}, 63 \%)$. $\operatorname{Rf}\left(\mathrm{H}_{2} \mathrm{O} /{ }^{\mathrm{i}} \mathrm{PrOH} / \mathrm{EtOAc} 1: 6: 3\right)=0.49 .{ }^{1} \mathrm{H}-\mathrm{NMR}\left(400 \mathrm{MHz}, \mathrm{DMSO}-\mathrm{d}_{6}\right) \delta(\mathrm{ppm}): 11.35(1 \mathrm{H}, \mathrm{s}, N-\mathrm{H}) ; 7.81$ $\left(1 \mathrm{H}, \mathrm{s},=\mathrm{CH}_{\text {triazol }}\right) ; 7.50(1 \mathrm{H}, \mathrm{d}, J=8.0 \mathrm{~Hz},=\mathrm{CH}) ; 5.73(1 \mathrm{H}, \mathrm{d}, J=5.29 \mathrm{~Hz}, \mathrm{CH}) ; 5.62(1 \mathrm{H}, \mathrm{d}, J=8.0 \mathrm{~Hz}$, $\mathrm{CH}) ; 4.62\left(2 \mathrm{H}, \mathrm{m}, \mathrm{CH}_{2}\right) ; 4.12(1 \mathrm{H}, \mathrm{m}, \mathrm{CH}) ; 4.04(1 \mathrm{H}, \mathrm{t}, J=5.28 \mathrm{~Hz}, \mathrm{CH}) ; 3.95(1 \mathrm{H}, \mathrm{t}, J=4.80 \mathrm{~Hz}, \mathrm{CH})$; $2.60\left(2 \mathrm{H}, \mathrm{t}, J=6.80 \mathrm{~Hz}, \mathrm{CH}_{2}\right) ; 2.22\left(2 \mathrm{H}, \mathrm{t}, J=7.26 \mathrm{~Hz}, \mathrm{CH}_{2}\right) ; 1.48-1.63\left(4 \mathrm{H}, \mathrm{m}, 2 \mathrm{CH}_{2}\right) .{ }^{13} \mathrm{C}-\mathrm{NMR}(100$ MHz, DMSO-d 6 ) $\delta$ (ppm): 174.9, 163.4, 151.1, 147.2, 141.5, 123.1, 102.5, 89.2, 82.2, 72.5, 71.0, 51.5, 33.9, 28.9, 25.1, 24.6. ESI-HRMS calculated for $\left[\mathrm{C}_{16} \mathrm{H}_{22} \mathrm{~N}_{5} \mathrm{O}_{7}\right]^{+} \mathrm{m} / z 396.1513$ and found $m / z 396.1512$. IR (neat, $\mathrm{cm}^{-1}$ ): $3142.7 b r ; 2929.3 \mathrm{~m} ; 1682.5 \mathrm{~s} ; 1461.3 w ; 1384.1 \mathrm{~m} ; 1261.9 \mathrm{~m} ; 1222.6 \mathrm{~m} ; 1100.1 \mathrm{~m} ; 1052.0 \mathrm{~m}$; 811.7w. $[\alpha]_{\mathrm{D}}{ }^{20}=+44.5(\mathrm{C}=0.015 \mathrm{M}, \mathrm{MeOH})$. LC-MS purity $95.2 \%, \mathrm{t}_{\mathrm{R}}=4.51 \mathrm{~min}$ water $/$ methanol (70:30 vol/vol, $0.1 \%$ of formic acid).

1-((2R,3R,4S,5R)-3,4-Dihydroxy-5-((4-(hydroxymethyl)-1H-1,2,3-triazol-1-yl)methyl)tetrahydrofuran-2-yl) pyrimidine-2,4(1H,3H)-dione (3d). According to the general procedure, copper(II) sulfate pentahydrate ( $6 \mathrm{mg}, 0.02 \mathrm{mmol}, 10 \mathrm{~mol} \%$ ) and sodium ascorbate $(28 \mathrm{mg}, 0.14 \mathrm{mmol}, 0.6 \mathrm{eq})$ were added to a solution of 5'-azido-5'-deoxyuridine $2(65 \mathrm{mg}, 0.24 \mathrm{mmol}, 1.0 \mathrm{eq})$ and propargyl alcohol ( $14 \mathrm{mg}, 0.24 \mathrm{mmol}$, 1.0 eq) with $t \mathrm{BuOH}: \mathrm{H}_{2} \mathrm{O}(4 \mathrm{~mL})$. The reaction mixture was stirred for $40 \mathrm{~min}$ at $40{ }^{\circ} \mathrm{C}$. The residue was purified by a flash chromatography $\left(\mathrm{H}_{2} \mathrm{O} / \mathrm{i} \mathrm{PrOH} / \mathrm{EtOAc}\right.$ 0.1:6.9:3) followed by a second flash 
chromatography (acetone/MeOH 9/1) to give the desired product as white solid (54 mg, 68\%). $\operatorname{Rf}\left(\mathrm{H}_{2} \mathrm{O} /{ }^{i} \mathrm{PrOH} / \mathrm{EtOAc} 1: 6: 3\right)=0.64 .{ }^{1} \mathrm{H}-\mathrm{NMR}\left(400 \mathrm{MHz}, \mathrm{DMSO}_{\mathrm{d}}\right) \delta(\mathrm{ppm}): 11.36(1 \mathrm{H}, \mathrm{s}, \mathrm{N}-\mathrm{H}) ; 7.92$ $\left(1 \mathrm{H}, \mathrm{s},=\mathrm{CH}_{\text {triazol }}\right) ; 7.50(1 \mathrm{H}, \mathrm{d}, J=8.05 \mathrm{~Hz},=\mathrm{CH}) ; 5.74(1 \mathrm{H}, \mathrm{d}, J=5.43 \mathrm{~Hz}, \mathrm{CH}) ; 5.63(1 \mathrm{H}, \mathrm{d}, J=7.97 \mathrm{~Hz}$, $=\mathrm{CH}) ; 5.50(1 \mathrm{H}, \mathrm{m}, \mathrm{O}-\mathrm{H}) ; 5.39(1 \mathrm{H}, \mathrm{m}, \mathrm{O}-\mathrm{H}) ; 5.18(1 \mathrm{H}, \mathrm{m}, \mathrm{O}-\mathrm{H}) ; 4.66\left(2 \mathrm{H}, \mathrm{m}, \mathrm{CH}_{2}\right) ; 4.50\left(2 \mathrm{H}, \mathrm{m}, \mathrm{CH}_{2}\right)$; $4.14(1 \mathrm{H}, \mathrm{m}, \mathrm{CH}) ; 4.03(1 \mathrm{H}, \mathrm{m}, \mathrm{CH}) ; 3.97(1 \mathrm{H}, \mathrm{m}, \mathrm{CH}) .{ }^{13} \mathrm{C}-\mathrm{NMR}\left(100 \mathrm{MHz}, \mathrm{DMSO}-\mathrm{d}_{6}\right) \delta$ (ppm): 163.4, $151.3,148.5,141.5,124.0,102.6,89.0,82.3,72.5,71.0,55.4,51.6$. ESI-HRMS calculated for $\left[\mathrm{C}_{12} \mathrm{H}_{16} \mathrm{~N}_{5} \mathrm{O}_{6}\right]^{+}$ $\mathrm{m} / \mathrm{z} 326.1095$ and found $\mathrm{m} / \mathrm{z}$ 326.1096. IR (neat, $\mathrm{cm}^{-1}$ ): 3436.5br; 3044.1w; 2922.1w; 1689.7s; 1459.5w; $1419.4 m ; 1390.6 m ; 1282.4 m ; 1081.1 m ; 1015.3 m ; 993.0 m ; 792.2 \mathrm{w} .[\alpha]_{\mathrm{D}}{ }^{20}=+47.6(\mathrm{C}=0.015 \mathrm{M}, \mathrm{MeOH})$. LC-MS purity $95 \%, \mathrm{t}_{\mathrm{R}}=8.36 \mathrm{~min}$ water $/$ methanol $(70: 30 \mathrm{vol} / \mathrm{vol}, 0.1 \%$ of formic acid).

1-((2R,3R,4S,5R)-3,4-Dihydroxy-5-((4-(2-hydroxyethyl)-1H-1,2,3-triazol-1-yl)methyl)tetrahydrofuran-2-yl) -pyrimidine-2,4(1H,3H)-dione (3e). According to the general procedure, copper(II) sulfate pentahydrate ( $6 \mathrm{mg}, 0.02 \mathrm{mmol}, 10 \mathrm{~mol} \%$ ) and sodium ascorbate ( $28 \mathrm{mg}, 0.14 \mathrm{mmol}, 0.6 \mathrm{eq}$ ) were added to a solution of 5'-azido-5'-deoxyuridine 2 ( $65 \mathrm{mg}, 0.24 \mathrm{mmol}, 1.0 \mathrm{eq})$ and 3-butyn-1-ol (17 mg, $0.24 \mathrm{mmol}, 1.0 \mathrm{eq})$ with $t \mathrm{BuOH}: \mathrm{H}_{2} \mathrm{O}(4 \mathrm{~mL})$. The reaction mixture was stirred for $35 \mathrm{~min}$ at $40{ }^{\circ} \mathrm{C}$. The residue was purified by a flash chromatography (acetone/ $\mathrm{MeOH} 98 / 2$ ) to give the desired product as white solid $(47 \mathrm{mg}, 57 \%) . \operatorname{Rf}\left(\mathrm{H}_{2} \mathrm{O} / \mathrm{PrOH} / \mathrm{EtOAc} 1: 6: 3\right)=0.61 .{ }^{1} \mathrm{H}-\mathrm{NMR}\left(400 \mathrm{MHz}, \mathrm{DMSO}-\mathrm{d}_{6}\right) \delta(\mathrm{ppm}): 11.36(1 \mathrm{H}$, $\mathrm{s}, N-\mathrm{H}) ; 7.82\left(1 \mathrm{H}, \mathrm{s},=\mathrm{CH}_{\text {triazol }}\right) ; 7.47(1 \mathrm{H}, \mathrm{d}, J=8.04 \mathrm{~Hz},=\mathrm{CH}) ; 5.74(1 \mathrm{H}, \mathrm{d}, J=5.23 \mathrm{~Hz}, \mathrm{CH}) ; 5.63(1 \mathrm{H}, \mathrm{d}$, $J=8.04 \mathrm{~Hz},=\mathrm{CH}) ; 4.63\left(2 \mathrm{H}, \mathrm{m}, \mathrm{CH}_{2}\right) ; 4.13(1 \mathrm{H}, \mathrm{m}, \mathrm{CH}) ; 4.00(1 \mathrm{H}, \mathrm{m}, \mathrm{CH}) ; 3.96(1 \mathrm{H}, \mathrm{m}, \mathrm{CH}) ; 3.62(2 \mathrm{H}, \mathrm{t}$, $\left.J=6.82 \mathrm{~Hz}, \mathrm{CH}_{2}\right) ; 2.76\left(2 \mathrm{H}, \mathrm{t}, J=6.85 \mathrm{~Hz}, \mathrm{CH}_{2}\right) .{ }^{13} \mathrm{C}-\mathrm{NMR}\left(100 \mathrm{MHz}, \mathrm{DMSO}-\mathrm{d}_{6}\right) \delta(\mathrm{ppm}): 163.4,151.1$, 145.0, 141.5, 123.7, 102.6, 89.0, 82.2, 72.5, 70.9, 60.8, 51.5, 29.6. ESI-HRMS calculated for $\left[\mathrm{C}_{13} \mathrm{H}_{18} \mathrm{~N}_{5} \mathrm{O}_{6}\right]^{+}$ $\mathrm{m} / \mathrm{z} 340.1251$ and found $\mathrm{m} / \mathrm{z} 340.1254$. IR (neat, $\mathrm{cm}^{-1}$ ): 3424.1br; 2921.2w; 1691.5s; $1461.8 w ; 1422.2 \mathrm{~m}$; $1382.2 m ; 1279.1 m ; 1233.6 m ; 1044.1 m ; 1018.1 m ; 995.7 m ; 809.7 \mathrm{w} .[\alpha]_{\mathrm{D}}{ }^{20}=+29.2(\mathrm{C}=0.03 \mathrm{M}, \mathrm{MeOH})$. LC-MS purity $94.2 \%, \mathrm{t}_{\mathrm{R}}=2.58 \mathrm{~min}$ water/methanol (70:30 vol/vol, $0.1 \%$ of formic acid).

1-((2R,3R,4S,5R)-3,4-Dihydroxy-5-((4-(3-hydroxypropyl)-1H-1,2,3-triazol-1-yl)methyl)tetrahydrofuran-2-yl) pyrimidine-2, $4(1 \mathrm{H}, 3 \mathrm{H})$-dione (3f). According to the general procedure, copper(II) sulfate pentahydrate ( $6 \mathrm{mg}, 0.02 \mathrm{mmol}, 10 \mathrm{~mol} \%$ ) and sodium ascorbate ( $30 \mathrm{mg}, 0.16 \mathrm{mmol}, 0.6 \mathrm{eq}$ ) were added to a solution of $5^{\prime}$-azido-5'-deoxyuridine 2 (70 mg, $\left.0.26 \mathrm{mmol}, 1.0 \mathrm{eq}\right)$ and 4-pentyn-1-ol (22 mg, $\left.0.26 \mathrm{mmol}, 1.0 \mathrm{eq}\right)$ with $t \mathrm{BuOH}: \mathrm{H}_{2} \mathrm{O}(4 \mathrm{~mL})$. The reaction mixture was stirred for $45 \mathrm{~min}$ at $40^{\circ} \mathrm{C}$. The residue was purified by a flash chromatography $\left(\mathrm{H}_{2} \mathrm{O} / \mathrm{PrOH} / \mathrm{EtOAc} 0.1: 6.9: 3\right)$ followed by a second flash chromatography (acetone/MeOH 95/5) to give the desired product as white solid $(57 \mathrm{mg}, 62 \%) . \mathrm{Rf}_{(}\left(\mathrm{H}_{2} \mathrm{O} / \mathrm{i} \mathrm{PrOH} / \mathrm{EtOAc}\right.$ 1:6:3) $=0.63 .{ }^{1} \mathrm{H}-\mathrm{NMR}\left(400 \mathrm{MHz}, \mathrm{DMSO}_{6}\right) \delta(\mathrm{ppm}): 11.36(1 \mathrm{H}, \mathrm{s}, \mathrm{N}-\mathrm{H}) ; 7.81\left(1 \mathrm{H}, \mathrm{s},=\mathrm{CH}_{\text {triazol }}\right) ; 7.48$ $(1 \mathrm{H}, \mathrm{d}, J=8.02 \mathrm{~Hz},=\mathrm{CH}) ; 5.74(1 \mathrm{H}, \mathrm{d}, J=5.55 \mathrm{~Hz}, \mathrm{CH}) ; 5.62(1 \mathrm{H}, \mathrm{d}, J=8.02 \mathrm{~Hz},=\mathrm{CH}) ; 5.49(1 \mathrm{H}, \mathrm{m}$, $\mathrm{O}-\mathrm{H}) ; 5.36(1 \mathrm{H}, \mathrm{m}, \mathrm{O}-\mathrm{H}) ; 4.62\left(2 \mathrm{H}, \mathrm{m}, \mathrm{CH}_{2}\right) ; 4.47(1 \mathrm{H}, \mathrm{m}, \mathrm{O}-\mathrm{H}) ; 4.13(1 \mathrm{H}, \mathrm{m}, \mathrm{CH}) ; 4.03(1 \mathrm{H}, \mathrm{m}, \mathrm{CH}) ; 3.96$ $(1 \mathrm{H}, \mathrm{m}, \mathrm{CH}) ; 3.42\left(2 \mathrm{H}, \mathrm{m}, \mathrm{CH}_{2}\right) ; 2.63\left(2 \mathrm{H}, \mathrm{t}, J=7.57 \mathrm{~Hz}, \mathrm{CH}_{2}\right) ; 1.72\left(2 \mathrm{H}, \mathrm{q}, J=6.77 \mathrm{~Hz}, \mathrm{CH}_{2}\right) .{ }^{13} \mathrm{C}-\mathrm{NMR}$ (100 MHz, DMSO-d 6 ) $\delta(\mathrm{ppm}): 163.5,151.1,147.3,141.5,123.1,102.5,89.1,82.2,72.5,71.0,60.5,51.5$, 32.7, 22.1. ESI-HRMS calculated for $\left[\mathrm{C}_{14} \mathrm{H}_{20} \mathrm{~N}_{5} \mathrm{O}_{6}\right]^{+} \mathrm{m} / z 354.1408$ and found $\mathrm{m} / z$ 354.1408. IR (neat, $\left.\mathrm{cm}^{-1}\right): 3367.9 \mathrm{br} ; 2945.1 \mathrm{~m} ; 1673.9 \mathrm{~s} ; 1462.5 \mathrm{~m} ; 1422.9 \mathrm{~m} ; 1384.7 \mathrm{~m} ; 1263.2 \mathrm{~m} ; 1224.0 \mathrm{~m} ; 1100.2 \mathrm{~m} ; 1051.8 \mathrm{~m}$; $811.9 \mathrm{w} \cdot[\alpha]_{\mathrm{D}}{ }^{20}=+58.0(\mathrm{C}=0.026 \mathrm{M}, \mathrm{MeOH})$. LC-MS purity $94.6 \%, \mathrm{t}_{\mathrm{R}}=3.24 \mathrm{~min}$ water $/ \mathrm{methanol}$ (70:30 vol/vol, $0.1 \%$ of formic acid).

1-((2R,3R,4S,5R)-5-((4-(Aminomethyl)-1H-1,2,3-triazol-1-yl)methyl)-3,4-dihydroxytetrahydrofuran-2-yl) -pyrimidine-2,4(1H,3H)-dione (3g). According to the general procedure, copper(II) sulfate pentahydrate (18.5 mg, $0.07 \mathrm{mmol}, 10 \mathrm{~mol} \%$ ) and sodium ascorbate $(88.3 \mathrm{mg}, 0.45 \mathrm{mmol}, 0.6 \mathrm{eq})$ were added to a solution of $5^{\prime}$-azido-5' -deoxyuridine $2(200 \mathrm{mg}, 0.74 \mathrm{mmol}, 1.0 \mathrm{eq})$ and propargyl amine $(61 \mathrm{mg}$, $1.10 \mathrm{mmol}, 1.5 \mathrm{eq})$ with $t \mathrm{BuOH}: \mathrm{H}_{2} \mathrm{O}(10 \mathrm{~mL})$. The reaction mixture was stirred for $1 \mathrm{~h}$ at $40{ }^{\circ} \mathrm{C}$. The residue was purified by a flash chromatography $\left(\mathrm{CHCl}_{3}: \mathrm{MeOH}: \mathrm{AcOH} 1: 1: 1\right)$ followed by a second flash chromatography $\left(\mathrm{H}_{2} \mathrm{O}: \mathrm{PrOH}: \mathrm{EtOAc}: \mathrm{AcOH}\right.$ 1:6:2:1) to give the desired product as white solid $(110 \mathrm{mg}, 46 \%) . \operatorname{Rf}\left(\mathrm{CHCl}_{3}: \mathrm{MeOH}: \mathrm{AcOH} 1: 1: 1\right)=0.28 .{ }^{1} \mathrm{H}-\mathrm{NMR}\left(400 \mathrm{MHz}, \mathrm{DMSO}-\mathrm{d}_{6}\right) \delta(\mathrm{ppm}):$ $7.88\left(1 \mathrm{H}, \mathrm{s},=\mathrm{CH}_{\text {triazol }}\right) ; 7.52(1 \mathrm{H}, \mathrm{d}, J=7.91 \mathrm{~Hz},=\mathrm{CH}) ; 5.74(1 \mathrm{H}, \mathrm{d}, J=4.90 \mathrm{~Hz}, \mathrm{CH}) ; 5.63(1 \mathrm{H}, \mathrm{d}$, $J=7.91 \mathrm{~Hz},=\mathrm{CH}) ; 4.64(2 \mathrm{H}, \mathrm{m}, \mathrm{CH}) ; 4.12(1 \mathrm{H}, \mathrm{m}, \mathrm{CH}) ; 4.01(1 \mathrm{H}, \mathrm{m}, \mathrm{CH}) ; 3.94(1 \mathrm{H}, \mathrm{m}, \mathrm{CH}) ; 3.77(2 \mathrm{H}$, 
m, $\left.\mathrm{CH}_{2}\right) .{ }^{13} \mathrm{C}-\mathrm{NMR}\left(100 \mathrm{MHz}, \mathrm{DMSO}_{-} \mathrm{d}_{6}\right) \delta$ (ppm): 163.5, 151.1, 149.1, 141.6, 123.3, 102.5, 89.3, 82.3, 72.7, 71.1, 51.7, 37.2. ESI-HRMS calculated for $\left[\mathrm{C}_{12} \mathrm{H}_{17} \mathrm{~N}_{6} \mathrm{O}_{5}\right]^{+} \mathrm{m} / \mathrm{z} 325.1254$ and found $\mathrm{m} / \mathrm{z} 325.1254$. IR (neat, $\mathrm{cm}^{-1}$ ): $3150.4 b r ; 1673.9 \mathrm{~s} ; 1462.5 \mathrm{~m} ; 1385.5 \mathrm{~m} ; 1263.1 \mathrm{~m} ; 1099.7 \mathrm{~m} ; 1050.8 \mathrm{~m} ; 812.3 \mathrm{w}$. $[\alpha]_{\mathrm{D}}{ }^{20}=+96.0$ $(\mathrm{C}=0.04 \mathrm{M}, \mathrm{MeOH})$. LC-MS purity $95.1 \%, \mathrm{t}_{\mathrm{R}}=0.72 \mathrm{~min}$ water/methanol $(70: 30 \mathrm{vol} / \mathrm{vol}, 0.1 \%$ of formic acid).

1-(((2R,3S,4R,5R)-5-(2,4-Dioxo-3,4-dihydropyrimidin-1(2H)-yl)-3,4-dihydroxytetrahydrofuran-2-yl)methyl)-1H -1,2,3-triazole-4-carboxamide (3h). According to the general procedure, copper(II) sulfate pentahydrate (18.5 mg, $0.07 \mathrm{mmol}, 10 \mathrm{~mol} \%)$ and sodium ascorbate $(88.3 \mathrm{mg}, 0.45 \mathrm{mmol}, 0.6 \mathrm{eq})$ were added to a solution of $5^{\prime}$-azido-5'-deoxyuridine $2(200 \mathrm{mg}, 0.74 \mathrm{mmol}, 1.0 \mathrm{eq})$ and propiolamide $(51 \mathrm{mg}$, $0.74 \mathrm{mmol}, 1.0 \mathrm{eq})$ with $t \mathrm{BuOH}: \mathrm{H}_{2} \mathrm{O}(10 \mathrm{~mL})$. The reaction mixture was stirred for $19 \mathrm{~h}$ at $40{ }^{\circ} \mathrm{C}$. The residue was purified by a flash chromatography (acetone/MeOH 9/1) followed by a second flash chromatography (EtOAc/MeOH 9/1) to give the desired product as white solid $(0.17 \mathrm{~g}, 68 \%)$. Rf (EtOAc:MeOH 9:1) = 0.21. ${ }^{1} \mathrm{H}-\mathrm{NMR}\left(400 \mathrm{MHz}, \mathrm{DMSO}_{\mathrm{d}}\right) \delta(\mathrm{ppm}): 11.37\left(1 \mathrm{H}, \mathrm{s}, \mathrm{N}-\mathrm{H}_{3}\right) ; 8.47(1 \mathrm{H}, \mathrm{s}$, $\left.=\mathrm{CH}_{\text {triazol }}\right) ; 7.85(1 \mathrm{H}, \mathrm{s}, \mathrm{N}-\mathrm{H}) ; 7.56(1 \mathrm{H}, \mathrm{d}, J=8.16 \mathrm{~Hz},=\mathrm{CH}) ; 7.46(1 \mathrm{H}, \mathrm{s}, \mathrm{N}-\mathrm{H}) ; 5.74(1 \mathrm{H}, \mathrm{d}, J=5.55 \mathrm{~Hz}$, $\mathrm{CH}) ; 5.63(1 \mathrm{H}, \mathrm{d}, J=8.16 \mathrm{~Hz}, \mathrm{CH}) ; 5.52(1 \mathrm{H}, \mathrm{d}, J=5.62 \mathrm{~Hz}, \mathrm{O}-\mathrm{H}) ; 5.40(1 \mathrm{H}, \mathrm{d}, J=5.34 \mathrm{~Hz}, \mathrm{O}-\mathrm{H}) ; 4.74(2 \mathrm{H}$, $\left.\mathrm{m}, \mathrm{CH}_{2}\right) ; 4.18(1 \mathrm{H}, \mathrm{m}, \mathrm{CH}) ; 4.11(1 \mathrm{H}, \mathrm{m}, \mathrm{CH}) ; 3.98(1 \mathrm{H}, \mathrm{m}, \mathrm{CH}) ; 3.77\left(2 \mathrm{H}, \mathrm{m}, \mathrm{CH}_{2}\right) .{ }^{13} \mathrm{C}-\mathrm{NMR}(100 \mathrm{MHz}$, DMSO-d $_{6}$ ) $\delta$ (ppm): 163.0, 161.5, 151.6, 142.9, 141.2, 127.2, 102.1, 88.9, 81.6, 72.1, 70.6, 51.5. ESI-HRMS calculated for $\left[\mathrm{C}_{12} \mathrm{H}_{15} \mathrm{~N}_{6} \mathrm{O}_{6}\right]^{+} \mathrm{m} / \mathrm{z} 339.1047$ and found $\mathrm{m} / \mathrm{z}$ 339.1048. IR (neat, $\mathrm{cm}^{-1}$ ): 3192.8br; 1690.5s; $1652.1 s ; 1466.2 w ; 1393.9 w ; 1266.7 w ; 1100.0 w ; 1045.7 w ; 819.8 w ; 779.5 w .[\alpha]_{\mathrm{D}}{ }^{20}=+37.9(\mathrm{C}=0.04 \mathrm{M}$, $\mathrm{MeOH}$ ). LC-MS purity $95.2 \%, \mathrm{t}_{\mathrm{R}}=1.94 \mathrm{~min}$ water/methanol (70:30 vol/vol, $0.1 \%$ of formic acid).

$N-((1-(((2 R, 3 S, 4 R, 5 R)-5-(2,4-D i o x o-3,4-d i h y d r o p y r i m i d i n-1(2 H)-y l)-3,4-d i h y d r o x y t e t r a h y d r o f u r a n-2-y l)$ methyl)-1H-1,2,3-triazol-4-yl)methyl)hexanamide (3i). According to the general procedure, copper(II) sulfate pentahydrate $(6 \mathrm{mg}, 0.02 \mathrm{mmol}, 10 \mathrm{~mol} \%)$ and sodium ascorbate $(28 \mathrm{mg}, 0.14 \mathrm{mmol}$, $0.6 \mathrm{eq})$ were added to a solution of $5^{\prime}$-azido-5'-deoxyuridine $2(65 \mathrm{mg}, 0.24 \mathrm{mmol}, 1.0 \mathrm{eq})$ and $\mathrm{N}$-(prop-2-yn-1-yl)hexanamide ( $37 \mathrm{mg}, 0.24 \mathrm{mmol}, 1.0 \mathrm{eq}$ ) with $t \mathrm{BuOH}: \mathrm{H}_{2} \mathrm{O}(3 \mathrm{~mL})$. The reaction mixture was stirred for $2 \mathrm{~h}$ at $40^{\circ} \mathrm{C}$. The residue was purified by a flash chromatography $\left(\mathrm{H}_{2} \mathrm{O} / \mathrm{irOH} / \mathrm{EtOAc}\right.$ 0.1:6.9:3) to give the desired product as white solid (99 mg, 99\%). $\mathrm{Rf}\left(\mathrm{H}_{2} \mathrm{O} / \mathrm{PrOH} / \mathrm{EtOAc} 1: 6: 3\right)=0.78$. ${ }^{1} \mathrm{H}-\mathrm{NMR}\left(400 \mathrm{MHz}, \mathrm{DMSO}-\mathrm{d}_{6}\right) \delta(\mathrm{ppm}): 11.38(1 \mathrm{H}, \mathrm{brs}, \mathrm{N}-\mathrm{H}) ; 8.27(1 \mathrm{H}, \mathrm{t}, J=5.68 \mathrm{~Hz}, \mathrm{~N}-\mathrm{H}) ; 7.85(1 \mathrm{H}, \mathrm{s}$, $\left.=\mathrm{CH}_{\text {triazol }}\right) ; 7.51(1 \mathrm{H}, \mathrm{d}, J=8.09 \mathrm{~Hz},=\mathrm{CH}) ; 5.75(1 \mathrm{H}, \mathrm{d}, J=5.24 \mathrm{~Hz}, \mathrm{CH}) ; 5.65(1 \mathrm{H}, \mathrm{d},=8.09 \mathrm{~Hz},=\mathrm{CH})$; $5.51(1 \mathrm{H}, \mathrm{d}, J=5.70 \mathrm{~Hz}, \mathrm{O}-\mathrm{H}) ; 5.39(1 \mathrm{H}, \mathrm{d}, J=5.22 \mathrm{~Hz}, \mathrm{O}-\mathrm{H}) ; 4.66\left(2 \mathrm{H}, \mathrm{m}, \mathrm{CH}_{2}\right) ; 4.27(2 \mathrm{H}, \mathrm{d}, J=5.70 \mathrm{~Hz}$, $\left.\mathrm{CH}_{2}\right) ; 4.13(1 \mathrm{H}, \mathrm{m}, \mathrm{CH}) ; 4.05(1 \mathrm{H}, \mathrm{m}, \mathrm{CH}) ; 3.96(1 \mathrm{H}, \mathrm{m}, \mathrm{CH}) ; 2.07\left(2 \mathrm{H}, \mathrm{t}, J=7.41 \mathrm{~Hz}, \mathrm{CH}_{2}\right) ; 1.49(2 \mathrm{H}$, $\left.\mathrm{m}, \mathrm{CH}_{2}\right), 1.16-1.30\left(4 \mathrm{H}, \mathrm{m}, 2 \mathrm{CH}_{2}\right) ; 0.84\left(3 \mathrm{H}, \mathrm{t}, J=6.78 \mathrm{~Hz}, \mathrm{CH}_{3}\right) .{ }^{13} \mathrm{C}-\mathrm{NMR}\left(100 \mathrm{MHz}, \mathrm{DMSO}-\mathrm{d}_{6}\right) \delta$ (ppm): 172.6, 163.4, 151.1, 145.6, 141.5, 124.0, 102.6, 89.0, 82.2, 72.5, 71.0, 51.6, 35.6, 34.5, 29.1, 26.0, 22.3, 14.3. ESI-HRMS calculated for $\left[\mathrm{C}_{18} \mathrm{H}_{27} \mathrm{~N}_{6} \mathrm{O}_{6}\right]^{+} \mathrm{m} / z 423.1986$ and found $m / z 423.1985$. IR (neat, $\mathrm{cm}^{-1}$ ): 3295.5br; 2930.2m; 2871.3m; 1682.4s; $1538.6 m ; 1462.0 m ; 1424.0 m ; 1381.3 m ; 1258.8 m ; 1101.1 m ; 1051.7 m$; 813.0w. $[\alpha]_{\mathrm{D}}{ }^{20}=+42.1(\mathrm{C}=0.02 \mathrm{M}, \mathrm{MeOH}) . \mathrm{LC}-\mathrm{MS}$ purity $95 \%, \mathrm{t}_{\mathrm{R}}=5.71 \mathrm{~min}$ water $/$ methanol $(70: 30$ $\mathrm{vol} / \mathrm{vol}, 0.1 \%$ of formic acid).

$N-((1-(((2 R, 3 S, 4 R, 5 R)-5-(2,4-D i o x o-3,4-d i h y d r o p y r i m i d i n-1(2 H)-y l)-3,4-d i h y d r o x y t e t r a h y d r o f u r a n-2-y l)$ methyl)-1H-1,2,3-triazol-4-yl)methyl)octanamide (3j). According to the general procedure, copper(II) sulfate pentahydrate $(6 \mathrm{mg}, 0.02 \mathrm{mmol}, 10 \mathrm{~mol} \%)$ and sodium ascorbate $(28 \mathrm{mg}, 0.14 \mathrm{mmol}$, $0.6 \mathrm{eq})$ were added to a solution of $5^{\prime}$-azido-5'-deoxyuridine $2(65 \mathrm{mg}, 0.24 \mathrm{mmol}, 1.0 \mathrm{eq})$ and $\mathrm{N}$-(prop-2-yn-1-yl)octanamide (44 mg, $0.24 \mathrm{mmol}, 1.0 \mathrm{eq}$ ) with $t \mathrm{BuOH}: \mathrm{H}_{2} \mathrm{O}(3 \mathrm{~mL})$. The reaction mixture was stirred for $2 \mathrm{~h}$ at $40^{\circ} \mathrm{C}$. The residue was purified by a flash chromatography $\left(\mathrm{H}_{2} \mathrm{O} / \mathrm{PrOH} / \mathrm{EtOAc}\right.$ 0.1:6.9:3) to give the desired product as white solid $(85 \mathrm{mg}, 77 \%)$. $R f\left(\mathrm{H}_{2} \mathrm{O} / \mathrm{PrOH} / \mathrm{EtOAc} 1: 6: 3\right)=0.81$. ${ }^{1} \mathrm{H}-\mathrm{NMR}(400 \mathrm{MHz}$, DMSO-d 6 ) $\delta(\mathrm{ppm}): 11.38(1 \mathrm{H}, \mathrm{brs}, \mathrm{N}-\mathrm{H}) ; 8.27(1 \mathrm{H}, \mathrm{t}, J=5.56 \mathrm{~Hz}, \mathrm{~N}-\mathrm{H}) ; 7.85(1 \mathrm{H}, \mathrm{s}$, $\left.=\mathrm{CH}_{\text {triazol }}\right) ; 7.51(1 \mathrm{H}, \mathrm{d}, J=8.06 \mathrm{~Hz},=\mathrm{CH}) ; 5.75(1 \mathrm{H}, \mathrm{d}, J=5.24 \mathrm{~Hz}, \mathrm{CH}) ; 5.65(1 \mathrm{H}, \mathrm{d}, J=8.06 \mathrm{~Hz},=\mathrm{CH})$; $5.51(1 \mathrm{H}, \mathrm{d}, J=5.67 \mathrm{~Hz}, \mathrm{O}-\mathrm{H}) ; 5.38(1 \mathrm{H}, \mathrm{d}, J=5.24 \mathrm{~Hz}, \mathrm{O}-\mathrm{H}) ; 4.66\left(2 \mathrm{H}, \mathrm{m}, \mathrm{CH}_{2}\right) ; 4.27(2 \mathrm{H}, \mathrm{d}, J=5.46 \mathrm{~Hz}$, $\left.\mathrm{CH}_{2}\right) ; 4.13(1 \mathrm{H}, \mathrm{m}, \mathrm{CH}) ; 4.05(1 \mathrm{H}, \mathrm{m}, \mathrm{CH}) ; 3.96(1 \mathrm{H}, \mathrm{m}, \mathrm{CH}) ; 2.07\left(2 \mathrm{H}, \mathrm{t}, J=7.34 \mathrm{~Hz}, \mathrm{CH}_{2}\right) ; 1.48(2 \mathrm{H}, \mathrm{m}$, $\left.\mathrm{CH}_{2}\right), 1.23\left(8 \mathrm{H}, \mathrm{m}, 4 \mathrm{CH}_{2}\right) ; 0.85\left(3 \mathrm{H}, \mathrm{t}, J=6.31 \mathrm{~Hz}, \mathrm{CH}_{3}\right) .{ }^{13} \mathrm{C}-\mathrm{NMR}\left(100 \mathrm{MHz}, \mathrm{DMSO}-\mathrm{d}_{6}\right) \delta(\mathrm{ppm}):$ 
172.6, 163.4, 151.1, 145.6, 141.4, 124.0, 102.6, 89.1, 82.2, 72.6, 71.0, 51.6, 35.7, 34.5, 31.6, 29.1, 28.9, 25.7, 22.5, 14.4. ESI-HRMS calculated for $\left[\mathrm{C}_{20} \mathrm{H}_{31} \mathrm{~N}_{6} \mathrm{O}_{6}\right]^{+} \mathrm{m} / z 451.2299$ and found $\mathrm{m} / z$ 451.2299. IR (neat, $\left.\mathrm{cm}^{-1}\right)$ : 3293.4br; 2927.2m; 2855.8m; 1682.3s; $1538.7 m ; 1462.1 \mathrm{~m} ; 1381.7 \mathrm{~m} ; 1263.1 \mathrm{~m} ; 1101.0 \mathrm{~m} ; 1052.4 \mathrm{~m}$; 812.0w. $[\alpha]_{\mathrm{D}}{ }^{20}=+61.4(\mathrm{C}=0.02 \mathrm{M}, \mathrm{MeOH})$. LC-MS purity $98.3 \%, \mathrm{t}_{\mathrm{R}}=7.63 \mathrm{~min}$ water $/ \mathrm{methanol}$ (70:30 vol/vol, $0.1 \%$ of formic acid).

Dimethyl 5-(1-(((2R,3S,4R,5R)-5-(2,4-dioxo-3,4-dihydropyrimidin-1(2H)-yl)-3,4-dihydroxytetrahydrofuran-2 -yl)methyl)-1H-1,2,3-triazol-4-yl)isophthalate (3k). According to the general procedure, copper(II) sulfate pentahydrate $(29 \mathrm{mg}, 0.11 \mathrm{mmol}, 10 \mathrm{~mol} \%)$ and sodium ascorbate $(136 \mathrm{mg}, 0.69 \mathrm{mmol}$, $0.6 \mathrm{eq})$ were added to a solution of $5^{\prime}$-azido-5'-deoxy-uridine $2(310 \mathrm{mg}, 1.14 \mathrm{mmol}, 1.0 \mathrm{eq})$ and dimethyl-5-ethynylisophathalate $(250 \mathrm{mg}, 1.14 \mathrm{mmol}, 1.0 \mathrm{eq})$ with $t \mathrm{BuOH}: \mathrm{H}_{2} \mathrm{O}(10 \mathrm{~mL})$. The reaction mixture was stirred for $5 \mathrm{~h} 30 \mathrm{~min}$ at $40{ }^{\circ} \mathrm{C}$. The residue was purified by a flash chromatography (DCM/MeOH 93/7 to 90/10) followed by a second flash chromatography (acetone/MeOH 99/1) to give the desired product as white solid $(0.40 \mathrm{~g}, 71 \%)$. Rf (DCM/MeOH 9:1) $=0.45 .{ }^{1} \mathrm{H}-\mathrm{NMR}(400 \mathrm{MHz}$, DMSO-d $\left._{6}\right) \delta(\mathrm{ppm}): 11.36(1 \mathrm{H}, \mathrm{s}, \mathrm{N}-\mathrm{H}) ; 8.91\left(1 \mathrm{H}, \mathrm{s},=\mathrm{CH}_{\text {triazol }}\right) ; 8.63(2 \mathrm{H}, \mathrm{s}, \mathrm{Ar}-\mathrm{H}) ; 8.39(1 \mathrm{H}, \mathrm{m}, \mathrm{Ar}-\mathrm{H})$; $7.56(1 \mathrm{H}, \mathrm{d}, J=8.09 \mathrm{~Hz},=\mathrm{CH}) ; 5.77(1 \mathrm{H}, \mathrm{d}, J=5.06 \mathrm{~Hz}, \mathrm{CH}) ; 5.59(1 \mathrm{H}, \mathrm{d}, J=8.09 \mathrm{~Hz},=\mathrm{CH}) ; 5.52(1 \mathrm{H}, \mathrm{d}$, $J=5.58 \mathrm{~Hz}, \mathrm{O}-\mathrm{H}) ; 5.41(1 \mathrm{H}, \mathrm{d}, J=5.46 \mathrm{~Hz}, \mathrm{O}-\mathrm{H}) ; 4.76\left(2 \mathrm{H}, \mathrm{m}, \mathrm{CH}_{2}\right) ; 4.25(1 \mathrm{H}, \mathrm{m}, \mathrm{CH}) ; 4.11(1 \mathrm{H}, \mathrm{m}, \mathrm{CH})$; $4.03(1 \mathrm{H}, \mathrm{m}, \mathrm{CH}) ; 3.92\left(6 \mathrm{H}, \mathrm{s}, 2 \mathrm{CH}_{3}\right) .{ }^{13} \mathrm{C}-\mathrm{NMR}\left(100 \mathrm{MHz}, \mathrm{DMSO}-\mathrm{d}_{6}\right) \delta(\mathrm{ppm}): 165.2,163.0,150.6$, 144.6, 141.2, 132.0, 131.0, 129.7, 128.6, 123.4, 102.1, 89.0, 82.5, 72.1, 70.5, 52.6, 51.6. ESI-HRMS calculated for $\left[\mathrm{C}_{21} \mathrm{H}_{22} \mathrm{~N}_{5} \mathrm{O}_{9}\right]^{+} \mathrm{m} / z 488.1412$ and found $\mathrm{m} / z$ 488.1411. IR (neat, $\mathrm{cm}^{-1}$ ): 3136.9br; 2955.2m; 1704.9s; $1467.1 m ; 1432.7 m ; 1302.5 m ; 1242.4 s ; 1204.8 m ; 1093.5 m ; 1057.2 m ; 996.4 w ; 819.5 w ; 753.7 \mathrm{w} .[\alpha]_{\mathrm{D}}{ }^{20}=+23.5$ $(\mathrm{C}=0.03 \mathrm{M}, \mathrm{MeOH})$. LC-MS purity $98.4 \%, \mathrm{t}_{\mathrm{R}}=7.21 \mathrm{~min}$ water/methanol $(70: 30 \mathrm{vol} / \mathrm{vol}, 0.1 \%$ of formic acid).

1-((2R,3R,4S,5R)-5-((4-(3,5-Dimethoxyphenyl)-1H-1,2,3-triazol-1-yl)methyl)-3,4-dihydroxytetrahydro-furan-2 -yl)pyrimidine-2,4(1H,3H)-dione (31). According to the general procedure, copper(II) sulfate pentahydrate (18.5 $\mathrm{mg}, 0.07 \mathrm{mmol}, 10 \mathrm{~mol} \%$ ) and sodium ascorbate $(88 \mathrm{mg}, 0.46 \mathrm{mmol}, 0.6 \mathrm{eq})$ were added to a solution of 5' -azido-5' -deoxyuridine $2(200 \mathrm{mg}, 0.74 \mathrm{mmol}, 1.0 \mathrm{eq})$ and 3,5-dimethoxyphenyl-1-ethynyl (120 mg, $0.74 \mathrm{mmol}, 1.0 \mathrm{eq}$ ) with $t \mathrm{BuOH}: \mathrm{H}_{2} \mathrm{O}(10 \mathrm{~mL})$. The reaction mixture was stirred for $17 \mathrm{~h}$ at $40{ }^{\circ} \mathrm{C}$. The residue was purified by a flash chromatography (DCM/MeOH 9/1) followed by a second flash chromatography (EtOAc/ $\mathrm{MeOH} 95 / 5)$ to give the desired product as white solid $(0.25 \mathrm{~g}, 78 \%)$. $\operatorname{Rf}(\mathrm{DCM} / \mathrm{MeOH} 9: 1)=0.33 .{ }^{1} \mathrm{H}-\mathrm{NMR}\left(400 \mathrm{MHz}, \mathrm{DMSO}_{6}\right) \delta(\mathrm{ppm}): 11.36(1 \mathrm{H}, \mathrm{d}, J=2.07 \mathrm{~Hz}, \mathrm{~N}-\mathrm{H})$; $8.60\left(1 \mathrm{H}, \mathrm{s},=\mathrm{CH}_{\text {triazol }}\right) ; 7.53(1 \mathrm{H}, \mathrm{d}, J=8.13 \mathrm{~Hz},=\mathrm{CH}) ; 7.02(2 \mathrm{H}, \mathrm{d}, J=2.24 \mathrm{~Hz}, 2 \mathrm{Ar}-\mathrm{H}) ; 6.47(1 \mathrm{H}, \mathrm{t}$, $J=2.24 \mathrm{~Hz}, \mathrm{Ar}-\mathrm{H}) ; 5.76(1 \mathrm{H}, \mathrm{d}, J=5.32 \mathrm{~Hz},=\mathrm{CH}) ; 5.58(1 \mathrm{H}, \mathrm{dd}, J=2.07 \mathrm{~Hz}, J=8.13 \mathrm{~Hz},=\mathrm{CH}) ; 5.51$ $(1 \mathrm{H}, \mathrm{d}, J=5.56 \mathrm{~Hz}, \mathrm{O}-\mathrm{H}) ; 5.40(1 \mathrm{H}, \mathrm{d}, J=5.45 \mathrm{~Hz}, \mathrm{O}-\mathrm{H}) ; 4.73\left(2 \mathrm{H}, \mathrm{m}, \mathrm{CH}_{2}\right) ; 4.21(1 \mathrm{H}, \mathrm{m}, \mathrm{CH}) ; 4.09(1 \mathrm{H}$, $\mathrm{m}, \mathrm{CH}) ; 4.02(1 \mathrm{H}, \mathrm{m}, \mathrm{CH}) ; 3.79\left(6 \mathrm{H}, \mathrm{s}, 2 \mathrm{CH}_{3}\right) .{ }^{13} \mathrm{C}-\mathrm{NMR}\left(100 \mathrm{MHz}, \mathrm{DMSO}-\mathrm{d}_{6}\right) \delta(\mathrm{ppm}): 163.0,160.9$, 150.6, 146.3, 141.2, 132.5, 122.5, 103.1, 102.0, 100.0, 88.9, 81.6, 72.1, 70.5, 55.3, 51.4. ESI-HRMS calculated for $\left[\mathrm{C}_{19} \mathrm{H}_{22} \mathrm{~N}_{5} \mathrm{O}_{7}\right]^{+} \mathrm{m} / \mathrm{z} 432.1513$ and found $\mathrm{m} / \mathrm{z}$ 432.1512. IR (neat, $\mathrm{cm}^{-1}$ ): 3233.9br; 2943.7w; 2840.0w; $1682.2 \mathrm{~s} ; 1596.2 \mathrm{~s} ; 1556.9 \mathrm{w} ; 1456.1 \mathrm{~m} ; 1423.2 \mathrm{~m} ; 1370.5 \mathrm{~m} ; 1265.4 \mathrm{~m} ; 1203.5 \mathrm{~m} ; 1153.1 \mathrm{~m} ; 1100.2 \mathrm{~m} ; 1043.8 \mathrm{~m}$; 925.4w; 809.6w; 685.8w. $[\alpha]_{\mathrm{D}}{ }^{20}=+74.7(\mathrm{C}=0.04 \mathrm{M}, \mathrm{MeOH})$. LC-MS purity $99.5 \%, \mathrm{t}_{\mathrm{R}}=6.94 \mathrm{~min}$ water/methanol (70:30 vol/vol, $0.1 \%$ of formic acid).

1-((2R,3R,4S,5R)-3,4-Dihydroxy-5-((4-(4-nitrophenyl)-1H-1,2,3-triazol-1-yl)methyl)tetrahydrofuran-2-yl) -pyrimidine-2,4(1H,3H)-dione $(3 \mathbf{m})$. According to the general procedure, copper(II) sulfate pentahydrate ( $18.5 \mathrm{mg}, 0.07 \mathrm{mmol}, 10 \mathrm{~mol} \%$ ) and sodium ascorbate $(88 \mathrm{mg}, 0.46 \mathrm{mmol}, 0.6 \mathrm{eq})$ were added to a solution of 5'-azido-5'-deoxyuridine $2(200 \mathrm{mg}, 0.74 \mathrm{mmol}, 1.0 \mathrm{eq})$ and 1-ethynyl-4-nitrophenyl $(110 \mathrm{mg}, 0.74 \mathrm{mmol}, 1.0 \mathrm{eq})$ with $t \mathrm{BuOH}: \mathrm{H}_{2} \mathrm{O}(10 \mathrm{~mL})$. The reaction mixture was stirred for $17 \mathrm{~h}$ at $40{ }^{\circ} \mathrm{C}$. The residue was purified by a flash chromatography (DCM/MeOH 92/8 to 90/10) followed by a second flash chromatography (EtOAc/MeOH 9/1) to give the desired product as white solid $(0.15 \mathrm{~g}$, 48\%). Rf (DCM/MeOH 9:1) = 0.26. ${ }^{1} \mathrm{H}-\mathrm{NMR}\left(400 \mathrm{MHz}, \mathrm{DMSO}^{-\mathrm{d}_{6}}\right) \delta(\mathrm{ppm}): 10.46(1 \mathrm{H}, \mathrm{s}, \mathrm{N}-\mathrm{H}) ; 9.11$ $\left(1 \mathrm{H}, \mathrm{s},=\mathrm{CH}_{\text {triazol }}\right) ; 8.77(2 \mathrm{H}, \mathrm{d}, J=8.46 \mathrm{~Hz}, 2 \mathrm{Ar}-\mathrm{H}) ; 8.63(2 \mathrm{H}, \mathrm{d}, J=8.46 \mathrm{~Hz}, 2 \mathrm{Ar}-\mathrm{H}) ; 7.88(1 \mathrm{H}, \mathrm{d}$, $J=8.08 \mathrm{~Hz},=\mathrm{CH}) ; 6.27(1 \mathrm{H}, \mathrm{m}, \mathrm{CH}) ; 5.97(1 \mathrm{H}, \mathrm{d}, J=8.08 \mathrm{~Hz},=\mathrm{CH}) ; 5.35\left(2 \mathrm{H}, \mathrm{m}, \mathrm{CH}_{2}\right) ; 5.23(1 \mathrm{H}$, 
$\mathrm{d}, J=4.28 \mathrm{~Hz}, \mathrm{O}-\mathrm{H}) ; 5.08(1 \mathrm{H}, \mathrm{d}, J=5.73 \mathrm{~Hz}, \mathrm{O}-\mathrm{H}) ; 4.71-4.85(3 \mathrm{H}, \mathrm{m}, 3 \mathrm{CH}) .{ }^{13} \mathrm{C}-\mathrm{NMR}(100 \mathrm{MHz}$, DMSO-d $_{6}$ ) $\delta$ (ppm): 162.9, 150.8, 147.3, 145.6, 141.6, 138.1, 126.6, 124.6, 124.2, 102.6, 92.1, 82.1, 73.4, 71.4, 51.9. ESI-HRMS calculated for $\left[\mathrm{C}_{17} \mathrm{H}_{17} \mathrm{~N}_{6} \mathrm{O}_{7}\right]^{+} m / z 417.1153$ and found $m / z 417.1153$. IR (neat, $\mathrm{cm}^{-1}$ ): 3104.2br; 2938.7w; 1674.4s; 1606.1m; 1514.7m; 1461.2m; 1378.7m; 1335.0s; 1238.2m; 1107.0m; 1043.4m; 853.4w; 813.0w; 756.0w. $[\alpha]_{\mathrm{D}}{ }^{20}=+57.7(\mathrm{C}=0.02 \mathrm{M}, \mathrm{MeOH})$. LC-MS purity $99.5 \%, \mathrm{t}_{\mathrm{R}}=6.49 \mathrm{~min}$ water/methanol (70:30 vol/vol, $0.1 \%$ of formic acid).

1-((2R,3R,4S,5R)-3,4-Dihydroxy-5-((4-(pyridin-2-yl)-1H-1,2,3-triazol-1-yl)methyl)tetrahydrofuran-2-yl) -pyrimidine-2,4(1H,3H)-dione (3n). According to the general procedure, copper(II) sulfate pentahydrate (18.5 $\mathrm{mg}, 0.07 \mathrm{mmol}, 10 \mathrm{~mol} \%$ ) and sodium ascorbate ( $88 \mathrm{mg}, 0.46 \mathrm{mmol}, 0.6 \mathrm{eq}$ ) were added to a solution of 5'-azido-5'-deoxyuridine 2 ( $200 \mathrm{mg}, 0.74 \mathrm{mmol}, 1.0 \mathrm{eq})$ and 2-ethynylpyridine $(0.11 \mathrm{~mL}, 1.11$ mmol, $1.5 \mathrm{eq})$ with $t \mathrm{BuOH}: \mathrm{H}_{2} \mathrm{O}(10 \mathrm{~mL})$. The reaction mixture was stirred for $19 \mathrm{~h}$ at $40{ }^{\circ} \mathrm{C}$. The residue was purified by a flash chromatography (DCM/MeOH 9/1) followed by a second flash chromatography (EtOAc/MeOH 95/5 to 90/10) to give the desired product as white solid (0.14 g, 50\%). Rf (DCM/MeOH 9:1) = 0.15. ${ }^{1} \mathrm{H}-\mathrm{NMR}\left(400 \mathrm{MHz}, \mathrm{DMSO}_{-} \mathrm{d}_{6}\right) \delta(\mathrm{ppm}): 11.36(1 \mathrm{H}, \mathrm{d}, J=2.05 \mathrm{~Hz}, \mathrm{~N}-\mathrm{H}) ; 8.58(1 \mathrm{H}, \mathrm{d}$, $J=4.71 \mathrm{~Hz}, \mathrm{Ar}-\mathrm{H}) ; 8.56\left(1 \mathrm{H}, \mathrm{s},=\mathrm{CH}_{\text {triazol }}\right) ; 8.03(1 \mathrm{H}, \mathrm{d}, J=7.77 \mathrm{~Hz}, \mathrm{Ar}-\mathrm{H}) ; 7.89(1 \mathrm{H}, \mathrm{td}, J=7.67 \mathrm{~Hz}$, $J=1.75 \mathrm{~Hz}, \mathrm{Ar}-\mathrm{H}) ; 7.60(1 \mathrm{H}, \mathrm{d}, J=8.06 \mathrm{~Hz},=\mathrm{CH}) ; 7.34(1 \mathrm{H}, \mathrm{dd}, J=1.15 \mathrm{~Hz}, J=4.86 \mathrm{~Hz}, \mathrm{Ar}-\mathrm{H}) ; 5.76$ $(1 \mathrm{H}, \mathrm{d}, J=5.57 \mathrm{~Hz}, \mathrm{CH}) ; 5.60(1 \mathrm{H}, \mathrm{dd}, J=2.05 \mathrm{~Hz}, J=8.06 \mathrm{~Hz},=\mathrm{CH}) ; 5.51(1 \mathrm{H}, \mathrm{d}, J=5.67 \mathrm{~Hz}, \mathrm{O}-\mathrm{H})$; $5.40(1 \mathrm{H}, \mathrm{d}, J=5.30 \mathrm{~Hz}, \mathrm{O}-\mathrm{H}) ; 4.77\left(2 \mathrm{H}, \mathrm{m}, \mathrm{CH}_{2}\right) ; 4.23(1 \mathrm{H}, \mathrm{q}, J=4.39 \mathrm{~Hz}, \mathrm{CH}) ; 4.11(1 \mathrm{H}, \mathrm{q}, J=5.52$ $\mathrm{Hz}, \mathrm{CH}) ; 4.02(1 \mathrm{H}, \mathrm{q}, J=5.06 \mathrm{~Hz}, \mathrm{CH}) .{ }^{13} \mathrm{C}-\mathrm{NMR}\left(100 \mathrm{MHz}, \mathrm{DMSO}_{\mathrm{d}}\right) \delta$ (ppm): 162.9, 150.6, 149.8, 149.6, 147.3, 141.1, 137.2, 124.0, 123.0, 119.4, 102.0, 88.7, 81.7, 72.0, 70.6, 51.4. ESI-HRMS calculated for $\left[\mathrm{C}_{16} \mathrm{H}_{17} \mathrm{~N}_{6} \mathrm{O}_{5}\right]^{+} \mathrm{m} / \mathrm{z} 373.1254$ and found $\mathrm{m} / \mathrm{z}$ 373.1254. IR (neat, $\mathrm{cm}^{-1}$ ): 3527.6w; 3433.8m; 3139.4w; $3067.3 w ; 2929.8 w ; 1764.0 w ; 1710.2 s ; 1686.9 s ; 1613.8 s ; 1555.9 w ; 1488.4 w ; 1464.3 m ; 1423.5 w ; 1379.6 w ;$ $1350.0 w ; 1325.4 w ; 1279.6 w ; 1250.8 m ; 1211.3 w ; 1191.3 w ; 1104.3 w ; 1062.1 m ; 1045.7 w ; 1027.9 w ; 943.4 w ;$ $898.5 w ; 859.7 w ; 814.5 w ; 788.3 w ; 717.7 w ; 628.5 w .[\alpha]_{\mathrm{D}}{ }^{20}=+46.4(\mathrm{C}=0.04 \mathrm{M}, \mathrm{MeOH})$. LC-MS purity $95.8 \%, \mathrm{t}_{\mathrm{R}}=4.33 \mathrm{~min}$ water $/ \mathrm{methanol}$ (70:30 vol/vol, $0.1 \%$ of formic acid).

1-((2R,3R,4S,5R)-3,4-Dihydroxy-5-((4-(thiophen-2-yl)-1H-1,2,3-triazol-1-yl)methyl)tetrahydrofuran-2-yl) -pyrimidine-2,4(1H,3H)-dione (3o). According to the general procedure, copper(II) sulfate pentahydrate (18.5 mg, $0.07 \mathrm{mmol}, 10 \mathrm{~mol} \%$ ) and sodium ascorbate ( $88 \mathrm{mg}, 0.46 \mathrm{mmol}, 0.6 \mathrm{eq})$ were added to a solution of 5'-azido-5'-deoxy-uridine $2(200 \mathrm{mg}, 0.74 \mathrm{mmol}, 1.0 \mathrm{eq})$ and 2-ethynylthiophene $(0.18 \mathrm{~mL}$, $1.86 \mathrm{mmol}, 2.5 \mathrm{eq})$ with $t \mathrm{BuOH}: \mathrm{H}_{2} \mathrm{O}(10 \mathrm{~mL})$. The reaction mixture was stirred for $19 \mathrm{~h}$ at $40{ }^{\circ} \mathrm{C}$. The residue was purified by a flash chromatography (DCM/MeOH 9/1) followed by a second flash chromatography (EtOAc/MeOH 95/5) to give the desired product as white solid $(0.20 \mathrm{~g}, 71 \%)$. $\mathrm{Rf}\left(\mathrm{DCM} / \mathrm{MeOH}\right.$ 9:1) = 0.26. ${ }^{1} \mathrm{H}-\mathrm{NMR}\left(400 \mathrm{MHz}, \mathrm{DMSO}-\mathrm{d}_{6}\right) \delta(\mathrm{ppm}): 11.36(1 \mathrm{H}, \mathrm{d}, J=2.20 \mathrm{~Hz}, \mathrm{~N}-\mathrm{H})$; $8.46\left(1 \mathrm{H}, \mathrm{s},=\mathrm{CH}_{\text {triazol }}\right) ; 7.54(1 \mathrm{H}, \mathrm{d}, J=8.15 \mathrm{~Hz},=\mathrm{CH}) ; 7.53(1 \mathrm{H}, \mathrm{dd}, J=1.17 \mathrm{~Hz}, J=5.15 \mathrm{~Hz}, \mathrm{Ar}-\mathrm{H})$; $7.43(1 \mathrm{H}, \mathrm{dd}, J=3.55 \mathrm{~Hz}, J=1.18 \mathrm{~Hz}, \mathrm{Ar}-\mathrm{H}) ; 7.12(1 \mathrm{H}, \mathrm{dd}, J=3.56 \mathrm{~Hz}, J=5.05 \mathrm{~Hz}, \mathrm{Ar}-\mathrm{H}) ; 5.76(1 \mathrm{H}, \mathrm{d}$, $J=5.33 \mathrm{~Hz}, \mathrm{CH}) ; 5.59(1 \mathrm{H}, \mathrm{dd}, J=2.20 \mathrm{~Hz}, J=8.15 \mathrm{~Hz},=\mathrm{CH}) ; 5.51(1 \mathrm{H}, \mathrm{d}, J=5.65 \mathrm{~Hz}, \mathrm{O}-\mathrm{H}) ; 5.39(1 \mathrm{H}$, $\mathrm{d}, J=5.46 \mathrm{~Hz}, \mathrm{O}-\mathrm{H}) ; 4.72\left(2 \mathrm{H}, \mathrm{m}, \mathrm{CH}_{2}\right) ; 4.20(1 \mathrm{H}, \mathrm{q}, J=4.42 \mathrm{~Hz}, \mathrm{CH}) ; 4.10(1 \mathrm{H}, \mathrm{q}, J=5.45 \mathrm{~Hz}, \mathrm{CH}) ; 4.00$ $(1 \mathrm{H}, \mathrm{q}, J=5.10 \mathrm{~Hz}, \mathrm{CH}) .{ }^{13} \mathrm{C}-\mathrm{NMR}\left(100 \mathrm{MHz}, \mathrm{DMSO}_{\mathrm{d}}\right) \delta(\mathrm{ppm}): 162.9,150.6,141.8,141.1,132.8$, $127.9,125.4,124.2,121.4,102.0,88.9,81.6,72.1,70.5,51.4$. ESI-HRMS calculated for $\left[\mathrm{C}_{15} \mathrm{H}_{16} \mathrm{~N}_{5} \mathrm{O}_{5} \mathrm{~S}\right]^{+}$ $\mathrm{m} / \mathrm{z} 378.0866$ and found $\mathrm{m} / \mathrm{z}$ 378.0866. IR (neat, $\mathrm{cm}^{-1}$ ): 3280.9br; 3108.2m; 2951.7w; 2900.9w; 1675.3s; $1634.1 \mathrm{~m} ; 1461.2 \mathrm{~m} ; 1418.2 w ; 1391.3 w ; 1356.5 w ; 1275.5 \mathrm{~m} ; 1226.6 w ; 1210.1 w ; 1138.1 w ; 1102.6 m ; 1064.0 m$; $1040.9 w ; 996.7 w ; 935.7 w ; 823.2 w ; 685.7 \mathrm{w} .[\alpha]_{\mathrm{D}}{ }^{20}=-24.3(\mathrm{C}=0.04 \mathrm{M}, \mathrm{MeOH})$. LC-MS purity $99.5 \%$, $\mathrm{t}_{\mathrm{R}}=5.84 \mathrm{~min}$ water/methanol (70:30 vol/vol, $0.1 \%$ of formic acid).

$(2 R, 3 R, 4 S, 5 R, 6 R)-2-($ Acetoxymethyl)-6-((1-(( $2 R, 3 S, 4 R, 5 R)-5-(2,4-$ dioxo-3,4-dihydropyrimidin-1(2H)-yl)3,4-dihydroxytetrahydrofuran-2-yl)methyl)-1H-1,2,3-triazol-4-yl)methoxy)tetrahydro-2H-pyran-3,4,5-triyl triacetate (3p). According to the general procedure, copper(II) sulfate pentahydrate (28 $\mathrm{mg}, 0.11 \mathrm{mmol}, 10 \mathrm{~mol} \%$ ) and sodium ascorbate $(132 \mathrm{mg}, 0.67 \mathrm{mmol}, 0.6 \mathrm{eq}$ ) were added to a solution of $5^{\prime}$-azido-5'-deoxyuridine $2(300 \mathrm{mg}, 1.11 \mathrm{mmol}, 1.0 \mathrm{eq})$ and 2-propynyl-tetra-O-acetyl- $\beta$-D-glucopyronoside $(430 \mathrm{mg}$, $1.11 \mathrm{mmol}, 1.0 \mathrm{eq})$ with $t \mathrm{BuOH}: \mathrm{H}_{2} \mathrm{O}(15 \mathrm{~mL})$. 
The reaction mixture was stirred for $6 \mathrm{~h}$ at $25^{\circ} \mathrm{C}$. The residue was purified by a flash chromatography (DCM/MeOH 93/7 to 90/10) followed by a second flash chromatography (acetone/MeOH 99/1) to give the desired product as white solid $(0.44 \mathrm{~g}, 60 \%)$. Rf (DCM/MeOH 9:1) =0.41. ${ }^{1} \mathrm{H}-\mathrm{NMR}(400 \mathrm{MHz}$, DMSO-d 6 ) $\delta$ (ppm): $11.35(1 \mathrm{H}, \mathrm{s}, N-\mathrm{H}) ; 8.03\left(1 \mathrm{H}, \mathrm{s},=\mathrm{CH}_{\text {triazol }}\right) ; 7.54(1 \mathrm{H}, \mathrm{d}, J=8.13 \mathrm{~Hz},=\mathrm{CH}) ; 5.74$ $(1 \mathrm{H}, \mathrm{d}, J=5.32 \mathrm{~Hz}, \mathrm{CH}) ; 5.64(1 \mathrm{H}, \mathrm{d}, J=8.08 \mathrm{~Hz},=\mathrm{CH}) ; 5.50(1 \mathrm{H}, \mathrm{d}, J=5.47 \mathrm{~Hz}, \mathrm{O}-\mathrm{H}) ; 5.38(1 \mathrm{H}, \mathrm{d}$, $J=5.28 \mathrm{~Hz}, \mathrm{O}-\mathrm{H}) ; 5.25(1 \mathrm{H}, \mathrm{t}, J=9.49 \mathrm{~Hz}, \mathrm{CH}) ; 4.87-4.95(2 \mathrm{H}, \mathrm{m}, 2 \mathrm{CH}) ; 4.60-4.83\left(5 \mathrm{H}, \mathrm{m}, 2 \mathrm{CH}_{2}, 1 \mathrm{CH}\right)$; 3.95-4.23 (6H, m, $\left.1 \mathrm{CH}_{2}, 4 \mathrm{CH}\right) ; 2.03\left(3 \mathrm{H}, \mathrm{s}, \mathrm{CH}_{3}\right) ; 1.98\left(3 \mathrm{H}, \mathrm{s}, \mathrm{CH}_{3}\right) ; 1.92\left(3 \mathrm{H}, \mathrm{s}, \mathrm{CH}_{3}\right) ; 1.90\left(3 \mathrm{H}, \mathrm{s}, \mathrm{CH}_{3}\right)$. ${ }^{13} \mathrm{C}-\mathrm{NMR}\left(100 \mathrm{MHz}, \mathrm{DMSO}-\mathrm{d}_{6}\right) \delta$ (ppm): 170.1, 169.5, 169.3, 169.0, 163.0, 150.6, 143.1, 141.2, 124.9, 102.1, 98.7, 88.9, 81.7, 72.0, 70.9, 70.7, 70.6, 68.1, 61.9, 61.7, 51.3, 20.5, 20.4, 20.3. ESI-HRMS calculated for $\left[\mathrm{C}_{26} \mathrm{H}_{34} \mathrm{~N}_{5} \mathrm{O}_{15}\right]^{+} m / z 656.2045$ and found $m / z$ 656.2044. IR (neat, $\mathrm{cm}^{-1}$ ): 3271.1br; 2954.3w; 1744.8s; $1688.5 s ; 1458.2 w ; 1429.5 w ; 1368.8 m ; 1217.4 s ; 1168.6 w ; 1034.9 s ; 905.3 w ; 813.4 w .[\alpha]_{D}^{20}=+4.5(C=0.02 \mathrm{M}$, $\mathrm{MeOH})$. LC-MS purity $95.3 \%, \mathrm{t}_{\mathrm{R}}=5.96 \mathrm{~min}$ water/methanol (70:30 vol/vol, $0.1 \%$ of formic acid).

(5-(1-(((2R,3S,4R,5R)-5-(2,4-Dioxo-3,4-dihydropyrimidin-1(2H)-yl)-3,4-dihydroxytetrahydrofuran-2-yl) -methyl)-1H-1,2,3-triazol-4-yl)pentanoyl)-L-alanine (4). According to the general procedure, copper(II) sulfate pentahydrate $(23 \mathrm{mg}, 0.09 \mathrm{mmol}, 10 \mathrm{~mol} \%$ ) and sodium ascorbate $(112 \mathrm{mg}, 0.56 \mathrm{mmol}, 0.6 \mathrm{eq})$ were added to a solution of $5^{\prime}$-azido-5'-deoxyuridine 2 (254 mg, $\left.0.94 \mathrm{mmol}, 1.0 \mathrm{eq}\right)$ and 6-heptynoic acid $(132 \mathrm{mg}, 0.94 \mathrm{mmol}, 1.0 \mathrm{eq})$ with $\mathrm{tBuOH}: \mathrm{H}_{2} \mathrm{O}(8 \mathrm{~mL})$. The reaction mixture was stirred for $1 \mathrm{~h}$ at $40{ }^{\circ} \mathrm{C}$. The residue was purified by a flash chromatography $\left(\mathrm{H}_{2} \mathrm{O} /{ }^{\mathrm{i}} \mathrm{PrOH} / \mathrm{EtOAc} 1: 6: 3\right)$ to give the desired product as white solid. The pure compound was dried under reduced pressure to remove residual water. Then, in a flame-dried round-bottom flask, the corresponding carboxylic acid derivative 3c (373 mg, $0.94 \mathrm{mmol}, 1.0 \mathrm{eq})$ was stirred with anhydrous DMF (10 mL) under argon atmosphere at $0{ }^{\circ} \mathrm{C}$. Then, BOP reagent ( $\left.417 \mathrm{mg}, 0.94 \mathrm{mmol}, 1.0 \mathrm{eq}\right), \mathrm{HOBt}(127 \mathrm{mg}, 0.94 \mathrm{mmol}, 1.0 \mathrm{eq})$, DIPEA (0.43 mL, $2.46 \mathrm{mmol}, 3.0 \mathrm{eq})$ and molecular sieves $4 \AA$ (one spatula) were successively added and stirred for $10 \mathrm{~min}$ at $0{ }^{\circ} \mathrm{C}$. Thus, L-alanine methyl ester hydrochloride (107 $\left.\mathrm{mg}, 1.04 \mathrm{eq}, 1.1 \mathrm{eq}\right)$ was added to the reaction mixture and stirred at $25{ }^{\circ} \mathrm{C}$ for $16 \mathrm{~h}$. The reaction was stopped and concentrated to dryness in vacuo with several co-evaporation with $\mathrm{n}$-heptane $(3 \times 15 \mathrm{~mL})$ to remove residual DMF. The residue was purified by flash chromatography $\left(\mathrm{H}_{2} \mathrm{O} /{ }^{\mathrm{I}} \mathrm{PrOH} / \mathrm{EA} 0.1 / 6.9 / 3\right)$ followed by a second flash chromatography (acetone/MeOH 96/4 to 90/10) to give a white solid. Then, the desired compound was directly deprotected without further characterization. This peptidic compound (40 mg, $0.08 \mathrm{mmol}, 1.0 \mathrm{eq})$ was stirred with THF: $\mathrm{H}_{2} \mathrm{O} 3: 1$ and lithium hydroxide monohydrate $(7 \mathrm{mg}$, $0.17 \mathrm{mmol}, 2.0 \mathrm{eq}$ ) was added to the reaction which was stirred for $18 \mathrm{~h}$ at $25^{\circ} \mathrm{C}$. Then, the reaction was quenched with $1 \mathrm{M} \mathrm{HCl}$ aqueous solution to $\mathrm{pH} 2$. The reaction mixture was concentrated to dryness in vacuo. Then, the residue was purified by a flash chromatography $\mathrm{SiO}_{2}-\mathrm{C}_{18}\left(\mathrm{H}_{2} \mathrm{O} 100 \%\right)$ to give the desired product as white solid (27 mg, 29\% in three steps). $\mathrm{Rf}\left(\mathrm{SiO}_{2}-\mathrm{C}_{18}-\mathrm{H}_{2} \mathrm{O} 100 \%\right)=0.18 .{ }^{1} \mathrm{H}-\mathrm{NMR}$ (400 MHz, DMSO-d 6 ) $\delta$ (ppm): $11.34(1 \mathrm{H}, \mathrm{d}, J=1.70 \mathrm{~Hz}, \mathrm{~N}-\mathrm{H}) ; 8.14(1 \mathrm{H}, \mathrm{d}, J=7.25 \mathrm{~Hz}, \mathrm{~N}-\mathrm{H}) ; 7.83(1 \mathrm{H}$, $\left.\mathrm{s},=\mathrm{CH}_{\text {triazol }}\right) ; 7.55(1 \mathrm{H}, \mathrm{d}, J=8.08 \mathrm{~Hz},=\mathrm{CH}) ; 5.73(1 \mathrm{H}, \mathrm{d}, J=5.36 \mathrm{~Hz}, \mathrm{CH}) ; 5.60(1 \mathrm{H}, \mathrm{dd}, J=1.70 \mathrm{~Hz}$, $J=8.08 \mathrm{~Hz},=\mathrm{CH}) ; 4.64\left(2 \mathrm{H}, \mathrm{m}, \mathrm{CH}_{2}\right) ; 4.10-4.22(2 \mathrm{H}, \mathrm{m}, 2 \mathrm{CH}) ; 4.06(1 \mathrm{H}, \mathrm{t}, J=5.38 \mathrm{~Hz}, \mathrm{CH}) ; 3.96(1 \mathrm{H}, \mathrm{t}$, $J=4.92 \mathrm{~Hz}, \mathrm{CH}) ; 2.59\left(2 \mathrm{H}, \mathrm{t}, J=6.84 \mathrm{~Hz}, \mathrm{CH}_{2}\right) ; 2.12\left(2 \mathrm{H}, \mathrm{t}, J=7.06 \mathrm{~Hz}, \mathrm{CH}_{2}\right) ; 1.45-1.61\left(4 \mathrm{H}, \mathrm{m}, 2 \mathrm{CH}_{2}\right)$; $1.23\left(3 \mathrm{H}, \mathrm{d}, J=7.31 \mathrm{~Hz}, \mathrm{CH}_{3}\right) .{ }^{13} \mathrm{C}-\mathrm{NMR}\left(100 \mathrm{MHz}, \mathrm{DMSO}-\mathrm{d}_{6}\right) \delta(\mathrm{ppm}): 174.2,171.9,163.0,150.6,146.8$, 141.2, 122.6, 102.0, 88.7, 81.8, 72.1, 70.5, 51.1, 47.4, 34.7, 28.5, 24.8, 24.7, 17.2. ESI-HRMS calculated for $\left[\mathrm{C}_{19} \mathrm{H}_{27} \mathrm{~N}_{6} \mathrm{O}_{8}\right]^{+} \mathrm{m} / z 467.1884$ and found $\mathrm{m} / \mathrm{z} 467.1882$. IR (neat, $\mathrm{cm}^{-1}$ ): 3366.2br; 3079.2w; 2942.8w; 2867.3w; 1686.6m; 1551.7w; 1460.3w; 1415.8w; 1384.4w; 1261.4w; 1217.1w; 1129.9w; 1102.5w; 1050.0s; 1022.8s; 998.9s; 825.5m; 764.6m; 630.7w. $[\alpha]_{\mathrm{D}}{ }^{20}=+20.6(\mathrm{C}=0.01 \mathrm{M}, \mathrm{MeOH})$. LC-MS purity $94.9 \%$, $\mathrm{t}_{\mathrm{R}}=4.37 \mathrm{~min}$ water/methanol (70:30 $\mathrm{vol} / \mathrm{vol}, 0.1 \%$ of formic acid).

N-((2S,3R,4R,5S,6R)-4,5-Dihydroxy-6-(hydroxymethyl)-2-(prop-2-yn-1-yloxy)tetrahydro-2H-pyran-3-yl) acetamide (6, CAS: 1000593-95-2). To a suspension of commercially N-acetyl-D-glucosamine 5 (1.0 g, $4.52 \mathrm{mmol}, 1.0 \mathrm{eq})$ in propargylic alcohol $(10 \mathrm{~mL}), 4 \AA$ molecular sieves (one spatula) was added under argon atmosphere. At $0^{\circ} \mathrm{C}$, trimetylsilyl triflate $(0.82 \mathrm{~mL}, 4.52 \mathrm{mmol}, 1.0 \mathrm{eq})$ was added drop by drop and the mixture was stirred at $0^{\circ} \mathrm{C}$ for an additional $5 \mathrm{~min}$ (until the fully solubilization of starting 
material). Then, the solution was stirred at $80{ }^{\circ} \mathrm{C}$ for $3 \mathrm{~h}$. Thus, the reaction was cooled at $0{ }^{\circ} \mathrm{C}$ and quenched with addition of solid $\mathrm{NaHCO}_{3}(3 \mathrm{~g})$. The suspension was filtered through a Celite pad and this was washed with methanol several times. The filtrate was concentrated to dryness in vacuo and the resulting residue was directly purified by a flash chromatography (DCM/MeOH 9/1) to give a brown solid. Then, the purified residue was dispersed with acetone $(10 \mathrm{~mL})$ and this was stirred at $50{ }^{\circ} \mathrm{C}$ for $1 \mathrm{~h}$. After, the suspension was cooled at $0{ }^{\circ} \mathrm{C}$ for $1 \mathrm{~h}$ and this was filtrated and washed with cold acetone (twice) to give a clean white solid $(0.61 \mathrm{~g}, 52 \%)$. Rf (DCM/MeOH 9:1) $=0.17 .{ }^{1} \mathrm{H}-\mathrm{NMR}$ (400 MHz, DMSO-d 6 ) $\delta$ (ppm): $7.75(1 \mathrm{H}, \mathrm{d}, J=8.25 \mathrm{~Hz}, N-\mathrm{H}) ; 5.01(1 \mathrm{H}, \mathrm{d}, J=5.62 \mathrm{~Hz}, \mathrm{O}-\mathrm{H}) ; 4.81(1 \mathrm{H}, \mathrm{d}$, $J=3.54 \mathrm{~Hz}, \mathrm{CH}) ; 4.73(1 \mathrm{H}, \mathrm{d}, J=5.74 \mathrm{~Hz}, \mathrm{O}-\mathrm{H}) ; 4.51(1 \mathrm{H}, \mathrm{t}, J=6.02 \mathrm{~Hz}, \mathrm{O}-\mathrm{H}) ; 4.18(2 \mathrm{H}, \mathrm{dd}, J=2.44 \mathrm{~Hz}$, $\left.J=15.95 \mathrm{~Hz}, \mathrm{CH}_{2}\right)$; 3.60-3.73 (2H, m, $\left.2 \mathrm{CH}\right) ; 3.43-3.50(2 \mathrm{H}, \mathrm{m}, 2 \mathrm{CH}) ; 3.42\left(1 \mathrm{H}, \mathrm{t}, J=2.39 \mathrm{~Hz}, \mathrm{CH}_{\text {alkyne }}\right)$; 3.32-3.37 (1H, m, CH); 3.11-3.18 (1H, m, CH); $1.83\left(3 \mathrm{H}, \mathrm{s}, \mathrm{CH}_{3}\right) .{ }^{13} \mathrm{C}-\mathrm{NMR}\left(100 \mathrm{MHz}, \mathrm{DMSO}_{6}\right) \delta$ (ppm): 169.4, 95.2, 79.7, 77.3, 73.2, 70.7, 70.5, 60.6, 53.4, 22.6. ESI-HRMS calculated for $\left[\mathrm{C}_{11} \mathrm{H}_{18} \mathrm{NO}_{6}\right]^{+}$ $\mathrm{m} / \mathrm{z} 260.1128$ and found $\mathrm{m} / \mathrm{z} 260.1126$. IR (neat, $\mathrm{cm}^{-1}$ ): 3585.7w; 3284.0s; 3079.5w; 2921.1w; 1632.5s; $1546.7 \mathrm{~s} ; 1412.9 w ; 1378.4 w ; 1320.1 w ; 1248.6 w ; 1113.0 m ; 1094.9 m ; 1029.0 s ; 1000.8 s ; 950.0 w ; 886.8 w ; 845.7 w ;$ 663.6w. $[\alpha]_{\mathrm{D}}{ }^{20}=+186.6(\mathrm{C}=0.06 \mathrm{M}, \mathrm{MeOH}) . \mathrm{CC}-\mathrm{MS}$ purity $96.6 \%, \mathrm{t}_{\mathrm{R}}=2.99 \mathrm{~min}$ water/methanol (70:30 vol/vol, $0.1 \%$ of formic acid).

$N-((2 S, 3 R, 4 R, 5 S, 6 R)-2-((1-(((2 R, 3 S, 4 R, 5 R)-5-(2,4-D i o x o-3,4-d i h y d r o p y r i m i d i n-1(2 H)-y l)-3,4-d i h y d r o x y-$ tetrahydrofuran-2-yl)methyl)-1H-1,2,3-triazol-4-yl)methoxy)-4,5-dihydroxy-6-(hydroxymethyl)tetrahydro-2H -pyran-3-yl)acetamide (7, CAS: 1152423-06-7). According to the general procedure, copper(II) sulfate pentahydrate $(19.3 \mathrm{mg}, 0.08 \mathrm{mmol}, 10 \mathrm{~mol} \%)$ and sodium ascorbate $(91.7 \mathrm{mg}, 0.46 \mathrm{mmol}$, $0.6 \mathrm{eq})$ were added to a solution of $5^{\prime}$-azido-5'-deoxyuridine 2 (208 mg, $\left.0.77 \mathrm{mmol}, 1.0 \mathrm{eq}\right)$ and 2-propynyl-N-acetyl- $\alpha$-D-glucosamine 6 (200 mg, $0.77 \mathrm{mmol}, 1.0 \mathrm{eq})$ with $t \mathrm{BuOH}: \mathrm{H}_{2} \mathrm{O}(15 \mathrm{~mL})$. The reaction mixture was stirred for $4 \mathrm{~h}$ at $40{ }^{\circ} \mathrm{C}$. The residue was purified by a flash chromatography (acetone/ $\mathrm{H}_{2} \mathrm{O}$ 95/5) followed by a second flash chromatography $\left(\mathrm{H}_{2} \mathrm{O} /{ }^{\mathrm{i}} \mathrm{PrOH} / \mathrm{EtOAc} 1 / 6 / 3\right)$ to give the desired product as white solid $(0.24 \mathrm{~g}, 59 \%)$. $\mathrm{Rf}\left(\mathrm{H}_{2} \mathrm{O} /{ }^{i} \mathrm{PrOH} / \mathrm{EtOAc} 1 / 6 / 3\right)=0.28 .{ }^{1} \mathrm{H}-\mathrm{NMR}(400 \mathrm{MHz}$, DMSO-d $\left._{6}\right) \delta$ (ppm): $11.36(1 \mathrm{H}, \mathrm{s}, N-\mathrm{H}) ; 8.08\left(1 \mathrm{H}, \mathrm{s},=\mathrm{CH}_{\text {tosyl }}\right) ; 7.68(1 \mathrm{H}, \mathrm{d}, J=8.17 \mathrm{~Hz}, N-\mathrm{H}) ; 7.58$ $(1 \mathrm{H}, \mathrm{d}, J=8.09 \mathrm{~Hz},=\mathrm{CH}) ; 5.74(1 \mathrm{H}, \mathrm{d}, J=5.38 \mathrm{~Hz}, \mathrm{CH}) ; 5.65(1 \mathrm{H}, \mathrm{d}, J=8.09 \mathrm{~Hz},=\mathrm{CH}) ; 5.51(1 \mathrm{H}$, $\mathrm{d}, J=5.64 \mathrm{~Hz}, \mathrm{O}-\mathrm{H}) ; 5.40(1 \mathrm{H}, \mathrm{d}, J=5.38 \mathrm{~Hz}, \mathrm{O}-\mathrm{H}) ; 4.99\left(1 \mathrm{H}, \mathrm{d}, \mathrm{J}_{\mathrm{H} 19^{\prime}}=5.34 \mathrm{~Hz}, \mathrm{O}-\mathrm{H}\right) ; 4.75(1 \mathrm{H}, \mathrm{d}$, $J=3.57 \mathrm{~Hz}, \mathrm{CH}) ; 4.60-4.74\left(4 \mathrm{H}, \mathrm{m}, \mathrm{O}-\mathrm{H} / \mathrm{CH}_{2} / \mathrm{CH}\right) ; 4.46-4.54(2 \mathrm{H}, \mathrm{m}, \mathrm{O}-\mathrm{H} / \mathrm{CH}) ; 4.06-4.17$ (2H, m, $\left.2 \mathrm{CH}\right)$; $3.97(1 \mathrm{H}, \mathrm{m}, \mathrm{CH}) ; 3.61-3.69(2 \mathrm{H}, \mathrm{m}, 2 \mathrm{CH}) ; 3.41-3.53(3 \mathrm{H}, \mathrm{m}, 3 \mathrm{CH}) ; 3.14(1 \mathrm{H}, \mathrm{m}, \mathrm{CH}) ; 1.78(3 \mathrm{H}, \mathrm{s}$, $\left.\mathrm{CH}_{3}\right) .{ }^{13} \mathrm{C}-\mathrm{NMR}\left(100 \mathrm{MHz}, \mathrm{DMSO}-\mathrm{d}_{6}\right) \delta(\mathrm{ppm}): 169.4,163.0,150.6,143.7,141.2,124.6,102.1,96.2$, 88.9, 81.7, 73.0, 72.0, 70.8, 70.5, 60.8, 59.8, 53.7, 51.3, 22.5. ESI-HRMS calculated for $\left[\mathrm{C}_{20} \mathrm{H}_{29} \mathrm{~N}_{6} \mathrm{O}_{11}\right]^{+}$ $\mathrm{m} / \mathrm{z} 529.1888$ and found $\mathrm{m} / \mathrm{z}$ 529.1883. IR (neat, $\mathrm{cm}^{-1}$ ): 3307.1br; 3099.6m; 2929.3m; 2833.5w; 1674.1s; $1548.6 w ; 1462.6 w ; 1423.5 w ; 1380.9 w ; 1320.9 w ; 1263.0 w ; 1101.1 m ; 1019.8 s ; 951.2 w ; 897.4 w ; 814.1 w ; 765.3 w ;$ 708.8w. $[\alpha]_{\mathrm{D}}{ }^{20}=+152.0\left(\mathrm{C}=0.03 \mathrm{M}, \mathrm{H}_{2} \mathrm{O}\right)$.LC-MS purity $95.5 \%, \mathrm{t}_{\mathrm{R}}=3.39 \mathrm{~min}$ water/methanol (70:30 vol/vol, $0.1 \%$ of formic acid).

((2R,3S,4R,5R,6S)-5-Acetamido-3,4-dihydroxy-6-(prop-2-yn-1-yloxy)tetrahydro-2H-pyran-2-yl)methyl4methylbenzenesulfonate (8, CAS: 1895096-35-1). To a solution of 2-propynyl- $N$-acetyl- $\alpha$-D-glucosamine 6 $(1.0 \mathrm{~g}, 3.86 \mathrm{mmol}, 1.0 \mathrm{eq})$ in adry pyridine $(15 \mathrm{~mL})$ at $0{ }^{\circ} \mathrm{C}$ under argon atmosphere, Tosyl chloride $(0.81 \mathrm{~g}, 4.24 \mathrm{mmol}, 1.1 \mathrm{eq})$ was added and the reaction was stirred at $25^{\circ} \mathrm{C}$ for $16 \mathrm{~h}$. After total conversion of starting material, the reaction mixture was stopped and concentrated to dryness in vacuo with co-evaporation once with toluene $(50 \mathrm{~mL})$ and once with cyclohexane $(50 \mathrm{~mL})$. The resulting residue was directly purified by a flash chromatography (DCM/MeOH 95/5) followed by a second chromatography (EtOAc 100\%) to give a white solid $(0.79 \mathrm{~g}, 50 \%)$. Rf (DCM/MeOH 9:1) $=0.38$. ${ }^{1} \mathrm{H}-\mathrm{NMR}\left(400 \mathrm{MHz}, \mathrm{DMSO}-\mathrm{d}_{6}\right) \delta(\mathrm{ppm}): 7.78(2 \mathrm{H}, \mathrm{d}, J=8.32 \mathrm{~Hz}, 2 \mathrm{Ar}-\mathrm{H}) ; 7.77(1 \mathrm{H}, \mathrm{m}, \mathrm{N}-\mathrm{H}) ; 7.48$ $(2 \mathrm{H}, \mathrm{d}, J=8.32 \mathrm{~Hz}, 2 \mathrm{Ar}-\mathrm{H}) ; 5.31(1 \mathrm{H}, \mathrm{d}, J=5.93 \mathrm{~Hz}, \mathrm{O}-\mathrm{H}) ; 4.86(1 \mathrm{H}, \mathrm{d}, J=6.06 \mathrm{~Hz}, \mathrm{O}-\mathrm{H}) ; 4.74(1 \mathrm{H}, \mathrm{d}$, $J=3.55 \mathrm{~Hz}, \mathrm{CH}) ; 4.18\left(2 \mathrm{H}, \mathrm{dd}, J=1.92 \mathrm{~Hz}, J=10.75 \mathrm{~Hz}, \mathrm{CH}_{2}\right) ; 4.11(2 \mathrm{H}, \mathrm{Dd}, J=2.44 \mathrm{~Hz}, J=16.11$ $\left.\mathrm{Hz}, \mathrm{CH}_{2}\right)$; $3.65(1 \mathrm{H}, \mathrm{m}, \mathrm{CH}) ; 3.55(1 \mathrm{H}, \mathrm{m}, \mathrm{CH}) ; 3.44\left(1 \mathrm{H}, \mathrm{t}, J=2.43 \mathrm{~Hz}, \mathrm{C}-\mathrm{H}_{\text {alkyne }}\right) ; 3.41(1 \mathrm{H}, \mathrm{m}, \mathrm{CH})$; $3.11(1 \mathrm{H}, \mathrm{m}, \mathrm{CH}) ; 2.43\left(3 \mathrm{H}, \mathrm{s}, \mathrm{CH}_{3}\right) ; 1.82\left(3 \mathrm{H}, \mathrm{s}, \mathrm{CH}_{3}\right) .{ }^{13} \mathrm{C}-\mathrm{NMR}\left(100 \mathrm{MHz}, \mathrm{DMSO}-\mathrm{d}_{6}\right) \delta(\mathrm{ppm}): 169.4$, 
144.9, 132.4, 130.1, 127.6, 95.4, 79.4, 77.5, 70.1, 70.0, 69.9, 53.9, 53.2, 22.5, 21.1. ESI-HRMS calculated for $\left[\mathrm{C}_{18} \mathrm{H}_{24} \mathrm{NO}_{8} \mathrm{~S}\right]^{+} \mathrm{m} / z 414.1217$ and found $\mathrm{m} / \mathrm{z}$ 414.1219. IR (neat, $\mathrm{cm}^{-1}$ ): 3282.0br; 2921.7w; 1651.6m; 1597.1w; 1538.1m; 1441.4w; 1353.7m; 1293.0w; 1189.4w; 1173.7s; 1122.2w; 1095.9w; 1032.0m; 996.2w; 969.2w; 929.4w; 891.5w; 813.4w; 664.8w. $[\alpha]_{\mathrm{D}}^{20}=+122.2(\mathrm{C}=0.07 \mathrm{M}, \mathrm{MeOH}) . \mathrm{CC}-\mathrm{MS}$ purity $94.3 \%$, $\mathrm{t}_{\mathrm{R}}=6.88 \mathrm{~min}$ water/methanol (70:30 $\mathrm{vol} / \mathrm{vol}, 0.1 \%$ of formic acid).

$((2 R, 3 S, 4 R, 5 R, 6 S)-5$-Acetamido-6-((1-(((2R,3S,4R,5R)-5-(2,4-dioxo-3,4-dihydropyrimidin-1(2H)-yl)-3,4dihydroxytetrahydrofuran-2-yl)methyl)-1H-1,2,3-triazol-4-yl)methoxy)-3,4-dihydroxytetrahydro-2H-pyran-2yl)methyl 4-methylbenzenesulfonate (9). According to the general procedure, copper(II) sulfate pentahydrate (47 mg, $0.19 \mathrm{mmol}, 10 \mathrm{~mol} \%$ ) and sodium ascorbate (220 mg, $1.12 \mathrm{mmol}, 0.6 \mathrm{eq})$ were added to a solution of 5'-azido-5'-deoxyuridine 2 (500 mg, $1.86 \mathrm{mmol}, 1.0 \mathrm{eq})$ and 6-tosylate-2-propynyl-N-acetyl- $\alpha$-D-glucosamine 8 (770 mg, $1.86 \mathrm{mmol}, 1.0 \mathrm{eq})$ with $t \mathrm{BuOH}: \mathrm{H}_{2} \mathrm{O}$ $(25 \mathrm{~mL})$. The reaction mixture was stirred for $2 \mathrm{~h}$ at $40{ }^{\circ} \mathrm{C}$. The residue was purified by a flash chromatography (acetone/ $\mathrm{H}_{2} \mathrm{O}$ 98/2) followed by a second flash chromatography $\left(\mathrm{H}_{2} \mathrm{O} /{ }^{\mathrm{i}} \mathrm{PrOH} / \mathrm{EtOAc}\right.$ $0.5 / 6.5 / 3)$ to give the desired product as colorless oil $(1.04 \mathrm{~g}, 82 \%)$. $\mathrm{Rf}\left(\mathrm{H}_{2} \mathrm{O} /{ }^{i} \mathrm{PrOH} / \mathrm{EtOAc} 1 / 6 / 3\right)=0.68$. ${ }^{1} \mathrm{H}-\mathrm{NMR}\left(400 \mathrm{MHz}, \mathrm{DMSO}-\mathrm{d}_{6}\right) \delta(\mathrm{ppm}): 11.36(1 \mathrm{H}, \mathrm{s}, \mathrm{N}-\mathrm{H}) ; 8.06\left(1 \mathrm{H}, \mathrm{s},=\mathrm{CH}_{\text {triazol }}\right) ; 7.79(2 \mathrm{H}, \mathrm{d}$, $J=8.35 \mathrm{~Hz}, 2 \mathrm{Ar}-\mathrm{H}) ; 7.70(1 \mathrm{H}, \mathrm{d}, J=8.12 \mathrm{~Hz}, N-\mathrm{H}) ; 7.58(1 \mathrm{H}, \mathrm{d}, J=8.12 \mathrm{~Hz},=\mathrm{CH}) ; 7.47(2 \mathrm{H}, \mathrm{d}$, $J=8.35 \mathrm{~Hz}, 2 \mathrm{Ar}-\mathrm{H}) ; 5.74(1 \mathrm{H}, \mathrm{d}, J=5.31 \mathrm{~Hz}, \mathrm{CH}) ; 5.64(1 \mathrm{H}, \mathrm{dd}, J=1.38 \mathrm{~Hz}, J=8.12 \mathrm{~Hz},=\mathrm{CH}) ; 5.51$ $(1 \mathrm{H}, \mathrm{d}, J=5.63 \mathrm{~Hz}, \mathrm{O}-\mathrm{H}) ; 5.40(1 \mathrm{H}, \mathrm{d}, J=5.44 \mathrm{~Hz}, \mathrm{O}-\mathrm{H}) ; 5.30(1 \mathrm{H}, \mathrm{d}, J=5.84 \mathrm{~Hz}, \mathrm{O}-\mathrm{H}) ; 4.83(1 \mathrm{H}, \mathrm{d}$, $J=6.01 \mathrm{~Hz}, \mathrm{O}-\mathrm{H}) ; 4.70(1 \mathrm{H}, \mathrm{d}, J=3.39 \mathrm{~Hz}, \mathrm{CH}) ; 4.60-4.74\left(2 \mathrm{H}, \mathrm{m}, \mathrm{CH}_{2}\right) ; 4.40-4.60\left(2 \mathrm{H}, \mathrm{m}, \mathrm{CH}_{2}\right) ; 4.24$ $(1 \mathrm{H}, \mathrm{m}, \mathrm{CH}) ; 4.10-4.17(3 \mathrm{H}, \mathrm{m}, 3 \mathrm{CH}) ; 3.98(1 \mathrm{H}, \mathrm{m}, \mathrm{CH}) ; 3.57-3.67(2 \mathrm{H}, \mathrm{m}, 2 \mathrm{CH}) ; 3.36-3.44(1 \mathrm{H}, \mathrm{m}, \mathrm{CH})$; 3.06-3.14 (1H, m, CH); $2.41\left(3 \mathrm{H}, \mathrm{s}, \mathrm{CH}_{3}\right) ; 1.76\left(3 \mathrm{H}, \mathrm{s}, \mathrm{CH}_{3}\right) .{ }^{13} \mathrm{C}-\mathrm{NMR}\left(100 \mathrm{MHz}, \mathrm{DMSO}-\mathrm{d}_{6}\right) \delta(\mathrm{ppm})$ : 169.5, 163.0, 150.6, 144.9, 143.5, 141.2, 132.4, 130.1, 127.6, 124.6, 102.1, 96.2, 88.9, 81.8, 72.0, 70.6, 70.2, $70.0,69.8,60.1,53.4,51.4,22.5,21.1$. ESI-HRMS calculated for $\left[\mathrm{C}_{27} \mathrm{H}_{35} \mathrm{~N}_{6} \mathrm{O}_{13} \mathrm{~S}\right]^{+} \mathrm{m} / z 683.1977$ and found $m / z$ 683.1963. IR (neat, $\mathrm{cm}^{-1}$ ): 3303.8br; 2929.2m; 2832.7w; 1682.4s; 1598.0w; 1548.6w; 1461.8w; $1427.3 w ; 1379.5 w ; 1351.8 m ; 1265.7 w ; 1189.5 w ; 1174.0 s ; 1123.3 m ; 1096.8 m ; 1020.2 m ; 998.7 m ; 969.6 w ;$ 931.0w; 813.2w; 768.8w; 666.1w. $[\alpha]_{\mathrm{D}}^{20}=+91.7(\mathrm{C}=0.02 \mathrm{M}, \mathrm{MeOH}) . \mathrm{LC}-\mathrm{MS}$ purity $98.3 \%, \mathrm{t}_{\mathrm{R}}=5.55 \mathrm{~min}$ water/methanol (70:30 vol/vol, $0.1 \%$ of formic acid).

N-((2S,3R,4R,5S,6R)-6-(Azidomethyl)-2-((1-(((2R,3S,4R,5R)-5-(2,4-dioxo-3,4-dihydropyrimidin-1(2H)-yl)-3,4 -dihydroxytetrahydrofuran-2-yl)methyl)-1H-1,2,3-triazol-4-yl)methoxy)-4,5-dihydroxytetrahydro-2H-pyran-3yl)acetamide (10). To flame dried round-bottom flask, compound $9(0.91 \mathrm{~g}, 1.33 \mathrm{mmol}, 1.0 \mathrm{eq})$ was stirred with dry DMF $(10 \mathrm{~mL})$ at $25^{\circ} \mathrm{C}$ under argon atmosphere. Then, sodium azide $(0.26 \mathrm{~g}, 3.99 \mathrm{mmol}, 3.0 \mathrm{eq})$ was added to the solution and this was stirred for $72 \mathrm{~h}$. Thus, the reaction mixture was concentrated to dryness in vacuo with co-evaporation with n-heptane to remove residual DMF. The residue was purified by a flash chromatography (acetonitrile/ $\mathrm{H}_{2} \mathrm{O} 9 / 1$ ) to give the desired product as white solid $(0.47 \mathrm{~g}, 64 \%)$. Rf (acetonitrile/ $\left.\mathrm{H}_{2} \mathrm{O} 9 / 1\right)=0.36 .{ }^{1} \mathrm{H}-\mathrm{NMR}\left(400 \mathrm{MHz}, \mathrm{DMSO}-\mathrm{d}_{6}\right) \delta(\mathrm{ppm}): 11.36(1 \mathrm{H}, \mathrm{s}$, $N-\mathrm{H}) ; 8.08\left(1 \mathrm{H}, \mathrm{s},=\mathrm{CH}_{\text {triazol }}\right) ; 7.74(1 \mathrm{H}, \mathrm{d}, J=8.12 \mathrm{~Hz}, \mathrm{~N}-\mathrm{H}) ; 7.59(1 \mathrm{H}, \mathrm{d}, J=8.09 \mathrm{~Hz},=\mathrm{CH}) ; 5.74(1 \mathrm{H}, \mathrm{d}$, $J=5.37 \mathrm{~Hz}, \mathrm{CH}) ; 5.65(1 \mathrm{H}, \mathrm{d}, J=8.09 \mathrm{~Hz},=\mathrm{CH}) ; 5.52(1 \mathrm{H}, \mathrm{d}, J=5.63 \mathrm{~Hz}, \mathrm{O}-\mathrm{H}) ; 5.40(1 \mathrm{H}, \mathrm{d}, J=5.33 \mathrm{~Hz}$, $\mathrm{O}-\mathrm{H}) ; 5.28(1 \mathrm{H}, \mathrm{m}, \mathrm{O}-\mathrm{H}) ; 4.82(1 \mathrm{H}, \mathrm{d}, \mathrm{J}=5.97 \mathrm{~Hz}, \mathrm{O}-\mathrm{H}) ; 4.80(1 \mathrm{H}, \mathrm{d}, \mathrm{J}=3.54 \mathrm{~Hz}, \mathrm{CH}) ; 4.61-4.75(2 \mathrm{H}$, $\left.\mathrm{m}, \mathrm{CH}_{2}\right)$; 4.51-4.70 (2H, m, CH); 4.09-4.18 (2H, m, $\left.2 \mathrm{CH}\right) ; 3.98(1 \mathrm{H}, \mathrm{m}, \mathrm{CH}) ; 3.61-3.72(2 \mathrm{H}, \mathrm{m}, 2 \mathrm{CH})$; 3.37-3.50 (3H, m, CH $/ \mathrm{CH}) ; 3.15(1 \mathrm{H}, \mathrm{m}, \mathrm{CH}) ; 1.78\left(3 \mathrm{H}, \mathrm{s}, \mathrm{CH}_{3}\right) .{ }^{13} \mathrm{C}-\mathrm{NMR}\left(100 \mathrm{MHz}, \mathrm{DMSO}-\mathrm{d}_{6}\right) \delta$ (ppm): 169.5, 163.0, 150.6, 143.5, 141.2, 124.6, 102.1, 96.5, 88.9, 81.7, 72.0, 71.5, 71.4, 70.6, 70.2, 60.2, 53.5, 51.3, 51.1, 22.5. ESI-HRMS calculated for $\left[\mathrm{C}_{20} \mathrm{H}_{28} \mathrm{~N}_{9} \mathrm{O}_{10}\right]^{+} \mathrm{m} / z$ 554.1953 and found $m / z$ 554.1949. IR (neat, $\mathrm{cm}^{-1}$ ): 3289.0br; 3258.4m;3193.2m;3151.7m;3077.0m; 2929.4br; 2722.4w; 2595.2w; 2101.1s; 1682.3s; 1577.6w; 1529.9w; 1546.7w; 1463.2w; 1421.5w; 1381.5w; 1318.7w; 1267.5w; 1234.2w; 1121.0m; $1098.4 m ; 1053.8 s ; 897.3 w ; 839.9 w ; 815.0 w ; 767.8 w .[\alpha]_{\mathrm{D}}{ }^{20}=+72.8(\mathrm{C}=0.01 \mathrm{M}, \mathrm{MeOH}) . \mathrm{LC}-\mathrm{MS}$ purity $94.0 \%, \mathrm{t}_{\mathrm{R}}=5.78 \mathrm{~min}$ water/methanol $(70: 30 \mathrm{vol} / \mathrm{vol}, 0.1 \%$ of formic acid $)$.

5-(1-(((2R,3S,4R,5R,6S)-5-Acetamido-6-((1-(((2R,3S,4R,5R)-5-(2,4-dioxo-3,4-dihydropyrimidin-1(2H)-yl)-3,4dihydroxytetrahydrofuran-2-yl)methyl)-1H-1,2,3-triazol-4-yl)methoxy)-3,4-dihydroxytetrahydro-2H-pyran-2-yl) methyl)-1H-1,2,3-triazol-4-yl)pentanoic acid (11a). According to the general procedure, copper(II) 
sulfate pentahydrate $(3.9 \mathrm{mg}, 0.02 \mathrm{mmol}, 10 \mathrm{~mol} \%)$ and sodium ascorbate $(18.5 \mathrm{mg}, 0.09 \mathrm{mmol}$, $0.6 \mathrm{eq})$ were added to a solution of compound $10(86 \mathrm{mg}, 0.16 \mathrm{mmol}, 1.0 \mathrm{eq})$ and 6-heptynoic acid $(26.1 \mathrm{mg}, 0.19 \mathrm{mmol}, 1.2 \mathrm{eq})$ with $t \mathrm{BuOH}: \mathrm{H}_{2} \mathrm{O}(10 \mathrm{~mL})$. The reaction mixture was stirred for $5 \mathrm{~h}$ at $40{ }^{\circ} \mathrm{C}$. The reaction was concentrated to dryness in vacuo with co-evaporation of methanol several times. The residue was purified by a flash chromatography $\left(\mathrm{H}_{2} \mathrm{O} /{ }^{i} \mathrm{PrOH} / \mathrm{EtOAc} 1 / 6 / 3\right)$ to give the desired product as white solid (87 mg, 82\%). Rf $\left(\mathrm{H}_{2} \mathrm{O} /{ }^{\mathrm{i}} \mathrm{PrOH} / \mathrm{EtOAc} 1 / 6 / 3\right)=0.23 .{ }^{1} \mathrm{H}-\mathrm{NMR}(400 \mathrm{MHz}$, DMSO-d 6 ) $\delta$ (ppm): $11.35(1 \mathrm{H}, \mathrm{s}, \mathrm{N}-\mathrm{H}) ; 7.93\left(1 \mathrm{H}, \mathrm{s},=\mathrm{CH}_{\text {triazol }}\right) ; 7.84\left(1 \mathrm{H}, \mathrm{s},=\mathrm{CH}_{\text {triazol }}\right) ; 7.77(1 \mathrm{H}, \mathrm{d}$, $J=8.17 \mathrm{~Hz}, N-\mathrm{H}) ; 7.59(1 \mathrm{H}, \mathrm{d}, J=8.09 \mathrm{~Hz},=\mathrm{CH}) ; 5.73(1 \mathrm{H}, \mathrm{d}, J=5.43 \mathrm{~Hz}, \mathrm{CH}) ; 5.64(1 \mathrm{H}, \mathrm{d}, J=8.09 \mathrm{~Hz}$, $=\mathrm{CH}) ; 4.71(1 \mathrm{H}, \mathrm{d}, J=3.42 \mathrm{~Hz}, \mathrm{CH}) ; 4.58-4.73\left(3 \mathrm{H}, \mathrm{m}, \mathrm{CH}_{2} / \mathrm{CH}\right) ; 4.37-4.45(1 \mathrm{H}, \mathrm{m}, \mathrm{CH}) ; 4.18-4.28(2 \mathrm{H}$, $\left.\mathrm{m}, \mathrm{CH}_{2}\right) ; 4.15(1 \mathrm{H}, \mathrm{m}, \mathrm{CH}) ; 4.06(1 \mathrm{H}, \mathrm{t}, J=5.38 \mathrm{~Hz}, \mathrm{CH}) ; 3.93(1 \mathrm{H}, \mathrm{m}, \mathrm{CH}) ; 3.82(1 \mathrm{H}, \mathrm{m}, \mathrm{CH}) ; 3.66$ $(1 \mathrm{H}, \mathrm{m}, \mathrm{CH}) ; 3.47(1 \mathrm{H}, \mathrm{m}, \mathrm{CH}) ; 3.07(1 \mathrm{H}, \mathrm{m}, \mathrm{CH}) ; 2.58\left(2 \mathrm{H}, \mathrm{t},=7.01 \mathrm{~Hz}, \mathrm{CH}_{2}\right) ; 2.05(2 \mathrm{H}, \mathrm{t}, J=7.05 \mathrm{~Hz}$, $\left.\mathrm{CH}_{2}\right) ; 1.76\left(3 \mathrm{H}, \mathrm{s}, \mathrm{CH}_{3}\right) ; 1.41-1.61\left(4 \mathrm{H}, \mathrm{m}, 2 \mathrm{CH}_{2}\right) .{ }^{13} \mathrm{C}-\mathrm{NMR}\left(100 \mathrm{MHz}, \mathrm{DMSO}-\mathrm{d}_{6}\right) \delta(\mathrm{ppm}): 175.7$, 169.5, 163.5, 150.6, 146.8, 143.0, 141.2, 124.6, 122.6, 102.1, 95.9, 89.0, 81.8, 72.1, 70.8, 70.6, 70.3, 59.4, 53.5, $51.3,50.6,35.0,28.8,24.9,24.7,22.5$. ESI-HRMS calculated for $\left[\mathrm{C}_{27} \mathrm{H}_{38} \mathrm{~N}_{9} \mathrm{O}_{12}\right]^{+} \mathrm{m} / z 680.2634$ and found $m / z$ 680.2627. IR (neat, $\mathrm{cm}^{-1}$ ): 3294.2br; 3149.3m;2927.8br; 2858.9m; 1689.3s; 1549.6m; 1461.5m; $1423.2 m ; 1380.5 m ; 1262.9 m ; 1224.5 m ; 1101.7 m ; 1053.1 m ; 1037.5 m ; 896.2 w ; 813.3 w ; 774.4 w ; 720.7 \mathrm{w}$. $[\alpha]_{\mathrm{D}}^{20}=+44.2(\mathrm{C}=0.01 \mathrm{M}, \mathrm{MeOH}) . \mathrm{LC}-\mathrm{MS}$ purity $96.7 \%, \mathrm{t}_{\mathrm{R}}=2.58 \mathrm{~min}$ water $/ \mathrm{methanol}(70: 30 \mathrm{vol} / \mathrm{vol}$, $0.1 \%$ of formic acid).

$N-((2 S, 3 R, 4 R, 5 S, 6 R)-6-((4-($ Aminomethyl)-1H-1,2,3-triazol-1-yl)methyl)-2-((1-(((2R,3S,4R,5R)-5-(2,4-dioxo3,4-dihydropyrimidin-1(2H)-yl)-3,4-dihydroxytetrahydrofuran-2-yl)methyl)-1H-1,2,3-triazol-4-yl)methoxy)-4,5 -dihydroxytetrahydro-2H-pyran-3-yl)acetamide (11b). According to the general procedure, copper(II) sulfate pentahydrate $(3.9 \mathrm{mg}, 0.02 \mathrm{mmol}, 10 \mathrm{~mol} \%)$ and sodium ascorbate $(18.5 \mathrm{mg}, 0.09 \mathrm{mmol}, 0.6 \mathrm{eq})$ were added to a solution of compound $10(86 \mathrm{mg}, 0.16 \mathrm{mmol}, 1.0 \mathrm{eq})$ and propargylamine $(12.8 \mathrm{mg}$, $0.23 \mathrm{mmol}, 1.5 \mathrm{eq})$ with $\mathrm{tBuOH}: \mathrm{H}_{2} \mathrm{O}(10 \mathrm{~mL})$. The reaction mixture was stirred for $5 \mathrm{~h}$ at $40{ }^{\circ} \mathrm{C}$. The reaction was concentrated to dryness in vacuo with co-evaporation of methanol several times. The residue was purified by a flash chromatography (Acetone/ $\mathrm{H}_{2} \mathrm{O}$ 95/5) to give the desired product as pale yellow solid $(18 \mathrm{mg}, 19 \%)$. Rf (acetone/ $\left.\mathrm{H}_{2} \mathrm{O} 95 / 5\right)=0.25$. ${ }^{1} \mathrm{H}-\mathrm{NMR}\left(400 \mathrm{MHz}, \mathrm{DMSO}-\mathrm{d}_{6}\right) \delta$ (ppm): $11.34(1 \mathrm{H}, \mathrm{s}, \mathrm{N}-\mathrm{H}) ; 8.79\left(1 \mathrm{H}, \mathrm{s},=\mathrm{CH}_{\text {triazol }}\right) ; 8.01\left(1 \mathrm{H}, \mathrm{s},=\mathrm{CH}_{\text {triazol }}\right) ; 7.74(1 \mathrm{H}, \mathrm{d}, J=8.13 \mathrm{~Hz}$, $N-\mathrm{H}) ; 7.58(1 \mathrm{H}, \mathrm{d}, J=8.10 \mathrm{~Hz},=\mathrm{CH}) ; 5.73(1 \mathrm{H}, \mathrm{d}, J=5.24 \mathrm{~Hz}, \mathrm{CH}) ; 5.63(1 \mathrm{H}, \mathrm{d}, J=8.07 \mathrm{~Hz}, \mathrm{CH}) ; 5.57$ $(1 \mathrm{H}, \mathrm{d}, J=5.13 \mathrm{~Hz}, \mathrm{O}-\mathrm{H}) ; 5.52(1 \mathrm{H}, \mathrm{d}, J=5.33 \mathrm{~Hz}, \mathrm{O}-\mathrm{H}) ; 5.42(1 \mathrm{H}, \mathrm{d}, J=4.92 \mathrm{~Hz}, \mathrm{O}-\mathrm{H}) ; 4.92(1 \mathrm{H}, \mathrm{d}, J$ $=5.74 \mathrm{~Hz}, \mathrm{O}-\mathrm{H}) ; 4.73(1 \mathrm{H}, \mathrm{d}, J=3.43 \mathrm{~Hz}, \mathrm{CH}) ; 4.57-4.82\left(3 \mathrm{H}, \mathrm{m}, \mathrm{CH}_{2} / \mathrm{CH}\right) ; 4.37-4.51(1 \mathrm{H}, \mathrm{m}, \mathrm{CH})$; 4.22-4.36 (2H, m, CH $)$; 4.05-4.18 (4H, m, N-H $/ \mathrm{CH} / \mathrm{CH}) ; 3.97(1 \mathrm{H}, \mathrm{m}, \mathrm{CH}) ; 3.88(1 \mathrm{H}, \mathrm{m}, \mathrm{CH}) ; 3.62(1 \mathrm{H}$, $\mathrm{m}, \mathrm{CH}) ; 3.48(1 \mathrm{H}, \mathrm{m}, \mathrm{CH}) ; 3.17(1 \mathrm{H}, \mathrm{d}, \mathrm{J}=5.03 \mathrm{~Hz}, \mathrm{CH}) ; 3.05(1 \mathrm{H}, \mathrm{m}, \mathrm{CH}) ; 1.76\left(3 \mathrm{H}, \mathrm{s}, \mathrm{CH}_{3}\right) .{ }^{13} \mathrm{C}-\mathrm{NMR}$ (100 MHz, DMSO-d 6 ) $\delta(p p m): 169.5,163.0,150.6,146.7,144.1$ 141.2, 129.3, 124.5, 102.1, 96.4, 89.0, 81.7, 72.0, 71.9, 70.6, 70.1, 59.9, 55.8, 51.3, 48.6, 22.4. ESI-HRMS calculated for $\left[\mathrm{C}_{23} \mathrm{H}_{30} \mathrm{~N}_{9} \mathrm{O}_{11}\right]^{+} \mathrm{m} / z$ 608.2059 and found $\mathrm{m} / z$ 608.2053. IR (neat, $\mathrm{cm}^{-1}$ ): 3275.5br; 2953.8m; 2922.9s; 2852.8m; 1688.6s; 1537.8w; $1463.0 w ; 1428.3 w ; 1379.6 w ; 1260.0 w ; 1231.2 w ; 1187.8 w ; 1126.1 w ; 1102.0 m ; 1083.0 m ; 1050.1 s ; 816.0 w ;$ 776.8w; 719.3w. $[\alpha]_{\mathrm{D}}{ }^{20}=+43.3\left(\mathrm{C}=0.03 \mathrm{M}, \mathrm{H}_{2} \mathrm{O}\right) . \mathrm{LC}-\mathrm{MS}$ purity $95.0 \%, \mathrm{t}_{\mathrm{R}}=2.22 \mathrm{~min}$ water $/ \mathrm{methanol}$ (70:30 vol/vol, $0.1 \%$ of formic acid).

1-(((2R,3S,4R,5R,6S)-5-Acetamido-6-((1-(((2R,3S,4R,5R)-5-(2,4-dioxo-3,4-dihydropyrimidin-1(2H)-yl)-3,4 -dihydroxytetrahydrofuran-2-yl)methyl)-1H-1,2,3-triazol-4-yl)methoxy)-3,4-dihydroxytetrahydro-2H-pyran-2yl)methyl)-1H-1,2,3-triazole-4-carboxamide (11c). According to the general procedure, copper(II) sulfate pentahydrate $(3.9 \mathrm{mg}, 0.02 \mathrm{mmol}, 10 \mathrm{~mol} \%)$ and sodium ascorbate $(18.5 \mathrm{mg}, 0.09 \mathrm{mmol}, 0.6 \mathrm{eq})$ were added to a solution of compound $10(86 \mathrm{mg}, 0.16 \mathrm{mmol}, 1.0 \mathrm{eq})$ and propiolamide $(12 \mathrm{mg}, 0.17 \mathrm{mmol}$, $1.1 \mathrm{eq})$ with $t \mathrm{BuOH}: \mathrm{H}_{2} \mathrm{O}(10 \mathrm{~mL})$. The reaction mixture was stirred for $5 \mathrm{~h}$ at $40^{\circ} \mathrm{C}$. The reaction was concentrated to dryness in vacuo with co-evaporation of methanol several times. The residue was purified by a flash chromatography $\left(\mathrm{H}_{2} \mathrm{O} /{ }^{\mathrm{i}} \mathrm{PrOH} / \mathrm{EtOAc} 1 / 6 / 3\right)$ to give the desired product as white solid (87 mg, 90\%). Rf (Acetone/ $\left.\mathrm{H}_{2} \mathrm{O} 95 / 5\right)=0.31 .{ }^{1} \mathrm{H}-\mathrm{NMR}\left(400 \mathrm{MHz}, \mathrm{DMSO}-\mathrm{d}_{6}\right) \delta(\mathrm{ppm}): 11.36(1 \mathrm{H}$, $\mathrm{s}, \mathrm{N}-\mathrm{H}) ; 8.45\left(1 \mathrm{H}, \mathrm{s},=\mathrm{CH}_{\text {triazol }}\right) ; 8.02\left(1 \mathrm{H}, \mathrm{s},=\mathrm{CH}_{\text {triazol }}\right) ; 7.84(1 \mathrm{H}, \mathrm{s}, \mathrm{N}-\mathrm{H}) ; 7.75(1 \mathrm{H}, \mathrm{d}, J=8.06 \mathrm{~Hz}, N-\mathrm{H})$; 
$7.59(1 \mathrm{H}, \mathrm{d}, J=8.06 \mathrm{~Hz},=\mathrm{CH}) ; 7.43(1 \mathrm{H}, \mathrm{s}, N-\mathrm{H}) ; 5.74(1 \mathrm{H}, \mathrm{d}, J=5.32 \mathrm{~Hz}, \mathrm{CH}) ; 5.65(1 \mathrm{H}, \mathrm{d}, J=8.04 \mathrm{~Hz}$, $=\mathrm{CH}) ; 4.74(1 \mathrm{H}, \mathrm{d}, J=3.38 \mathrm{~Hz}, \mathrm{CH}) ; 4.53-4.78\left(4 \mathrm{H}, \mathrm{m}, \mathrm{CH} / \mathrm{CH}_{2}\right) ; 4.24-4.37\left(2 \mathrm{H}, \mathrm{m}, \mathrm{CH}_{2}\right) ; 4.10-4.18$ $(2 \mathrm{H}, \mathrm{m}, 2 \mathrm{CH}) ; 3.98(1 \mathrm{H}, \mathrm{m}, \mathrm{CH}) ; 3.89(1 \mathrm{H}, \mathrm{m}, \mathrm{CH}) ; 3.63(1 \mathrm{H}, \mathrm{m}, \mathrm{CH}) ; 3.49(1 \mathrm{H}, \mathrm{m}, \mathrm{CH}) ; 3.04(1 \mathrm{H}, \mathrm{t}$, $J=9.22 \mathrm{~Hz}, \mathrm{CH}) ; 1.76\left(3 \mathrm{H}, \mathrm{s}, \mathrm{CH}_{3}\right) .{ }^{13} \mathrm{C}-\mathrm{NMR}\left(100 \mathrm{MHz}, \mathrm{DMSO}_{6}\right) \delta(\mathrm{ppm}): 169.5,163.0,161.6,150.6$, 143.5, 142.7, 141.3, 127.6, 124.5, 102.1, 96.3, 89.0, 81.8, 72.0, 71.9, 70.6, 70.2, 59.9, 53.5, 51.4, 50.9, 22.5 . ESI-HRMS calculated for $\left[\mathrm{C}_{23} \mathrm{H}_{31} \mathrm{~N}_{10} \mathrm{O}_{11}\right]^{+} \mathrm{m} / z 623.2168$ and found $\mathrm{m} / z$ 623.2164. IR (neat, $\mathrm{cm}^{-1}$ ): 3304.7br; 2922.8m; 2851.5w; 1667.0s; 1556.8m; 1463.0m; 1423.1m; 1382.1m; 1322.8w; 1263.2m; 1232.2m; $1101.2 m ; 1049.8 s ; 1019.6 s ; 896.1 w ; 814.8 w ; 773.3 w .[\alpha]_{\mathrm{D}}{ }^{20}=+62.8(\mathrm{C}=0.02 \mathrm{M}, \mathrm{MeOH}) . \mathrm{LC}-\mathrm{MS}$ purity $96.1 \%, \mathrm{t}_{\mathrm{R}}=2.88 \mathrm{~min}$ water/methanol (70:30 vol/vol, $0.1 \%$ of formic acid).

$N$ - $((1-(((2 R, 3 S, 4 R, 5 R, 6 S))-5$-Acetamido-6-((1-(((2R,3S,4R,5R)-5-(2,4-dioxo-3,4-dihydropyrimidin-1(2H)-yl)-3,4 -dihydroxytetrahydrofuran-2-yl)methyl)-1H-1,2,3-triazol-4-yl)methoxy)-3,4-dihydroxytetrahydro-2H-pyran-2 -yl)methyl)-1H-1,2,3-triazol-4-yl)methyl)octanamide (11d). According to the general procedure, copper(II) sulfate pentahydrate $(3.9 \mathrm{mg}, 0.02 \mathrm{mmol}, 10 \mathrm{~mol} \%)$ and sodium ascorbate $(18.5 \mathrm{mg}, 0.09 \mathrm{mmol}, 0.6 \mathrm{eq})$ were added to a solution of compound $10(86 \mathrm{mg}, 0.16 \mathrm{mmol}, 1.0 \mathrm{eq})$ and $\mathrm{N}$-(prop-2-yn-1-yl)octanamide ( $31 \mathrm{mg}, 0.17 \mathrm{mmol}, 1.1 \mathrm{eq}$ ) with $t \mathrm{BuOH}: \mathrm{H}_{2} \mathrm{O}(10 \mathrm{~mL})$. The reaction mixture was stirred for $5 \mathrm{~h}$ at $40{ }^{\circ} \mathrm{C}$. The reaction was concentrated to dryness in vacuo with co-evaporation of methanol several times. The residue was purified by a flash chromatography (acetone $/ \mathrm{H}_{2} \mathrm{O} 95 / 5$ ) to give the desired product as white solid ( $88 \mathrm{mg}$, 78\%). Rf (acetone $\left./ \mathrm{H}_{2} \mathrm{O} 95 / 5\right)=0.38 .{ }^{1} \mathrm{H}-\mathrm{NMR}\left(400 \mathrm{MHz}, \mathrm{DMSO}-\mathrm{d}_{6}\right) \delta(\mathrm{ppm}): 11.35$ $(1 \mathrm{H}, \mathrm{d}, J=1.30 \mathrm{~Hz}, \mathrm{~N}-\mathrm{H}) ; 8.23(1 \mathrm{H}, \mathrm{t}, J=5.64 \mathrm{~Hz}, \mathrm{~N}-\mathrm{H}) ; 7.99\left(1 \mathrm{H}, \mathrm{s},=\mathrm{CH}_{\text {triazol }}\right) ; 7.84\left(1 \mathrm{H}, \mathrm{s},=\mathrm{CH}_{\text {triazol }}\right)$; $7.72(1 \mathrm{H}, \mathrm{d}, J=8.16 \mathrm{~Hz}, \mathrm{~N}-\mathrm{H}) ; 7.59(1 \mathrm{H}, \mathrm{d}, J=8.07 \mathrm{~Hz},=\mathrm{CH}) ; 5.74(1 \mathrm{H}, \mathrm{d}, J=5.35 \mathrm{~Hz}, \mathrm{CH}) ; 5.64(1 \mathrm{H}$, $\mathrm{dd}, J=1.30 \mathrm{~Hz}, J=8.07 \mathrm{~Hz},=\mathrm{CH}) ; 5.51(1 \mathrm{H}, \mathrm{d}, J=5.63 \mathrm{~Hz}, \mathrm{O}-\mathrm{H}) ; 5.47(1 \mathrm{H}, \mathrm{d}, J=5.79 \mathrm{~Hz}, \mathrm{O}-\mathrm{H}) ; 5.40$ $(1 \mathrm{H}, \mathrm{d}, J=5.43 \mathrm{~Hz}, \mathrm{O}-\mathrm{H}) ; 4.88(1 \mathrm{H}, \mathrm{d}, J=5.79 \mathrm{~Hz}, \mathrm{O}-\mathrm{H}) ; 4.71(1 \mathrm{H}, \mathrm{d}, J=3.57 \mathrm{~Hz}, \mathrm{CH}) ; 4.60-4.74(3 \mathrm{H}, \mathrm{m}$, $\left.\mathrm{CH} / \mathrm{CH}_{2}\right) ; 4.44-4.51(1 \mathrm{H}, \mathrm{m}, \mathrm{CH}) ; 4.22-4.37\left(4 \mathrm{H}, \mathrm{m}, 2 \mathrm{CH}_{2}\right) ; 4.07-4.18(2 \mathrm{H}, \mathrm{m}, 2 \mathrm{CH}) ; 3.98(1 \mathrm{H}, \mathrm{m}, \mathrm{CH})$; $3.83(1 \mathrm{H}, \mathrm{m}, \mathrm{CH}) ; 3.63(1 \mathrm{H}, \mathrm{m}, \mathrm{CH}) ; 3.47(1 \mathrm{H}, \mathrm{m}, \mathrm{CH}) ; 3.05(1 \mathrm{H}, \mathrm{m}, \mathrm{CH}) ; 2.03\left(3 \mathrm{H}, \mathrm{t}, J=7.35 \mathrm{~Hz}, \mathrm{CH}_{3}\right)$; $1.76\left(3 \mathrm{H}, \mathrm{s}, \mathrm{H}_{29^{\prime}}\right) ; 1.44\left(2 \mathrm{H}, \mathrm{m}, \mathrm{CH}_{2}\right) ; 1.15-1.28\left(8 \mathrm{H}, \mathrm{m}, 4 \mathrm{CH}_{2}\right) ; 0.84\left(3 \mathrm{H}, \mathrm{t}, J=6.70 \mathrm{~Hz}, \mathrm{CH}_{3}\right) .{ }^{13} \mathrm{C}-\mathrm{NMR}$ (100 MHz, DMSO-d 6 ) $\delta$ (ppm): 172.1, 169.5, 163.0 150.6, 144.9, 143.2, 141.2, 124,6, 123.7, 102.1, 96.1, 88.9, 81.7, 72.0, 71.9, 70.6, 70.5, 70.2, 59.8, 53.4, 51.4, 50.5, 35.2, 34.1, 31.1, 28.6, 28.4, 25.2, 22.5, 22.0, 13.9. ESI-HRMS calculated for $\left[\mathrm{C}_{31} \mathrm{H}_{47} \mathrm{~N}_{10} \mathrm{O}_{11}\right]^{+} m / z 735.3420$ and found $m / z 735.3421$. IR (neat, $\mathrm{cm}^{-1}$ ): 3291.1br; 2928.4s; 2855.8m; 1682.8s; 1540.6m; 1461.6m; 1427.5m; 1379.1 m; 1264.0m; 1227.8m; 1102.8m; $1052.8 s ; 814.2 w ; 776.8 w ; 720.7 w .[\alpha]_{D}{ }^{20}=+79.0(\mathrm{C}=0.02 \mathrm{M}, \mathrm{MeOH}) . \mathrm{LC}-\mathrm{MS}$ purity $95.2 \%, \mathrm{t}_{\mathrm{R}}=3.42 \mathrm{~min}$ water/methanol (70:30 vol/vol, $0.1 \%$ of formic acid).

$\mathrm{N}-((2 S, 3 R, 4 R, 5 S, 6 R)-6-((4-)(((2 S, 3 R, 4 R, 5 S, 6 R)-3-$ Acetamido-4,5-dihydroxy-6-(hydroxymethyl)tetrahydro-2H -pyran-2-yl)oxy)methyl)-1H-1,2,3-triazol-1-yl)methyl)-2-((1-(((2R,3S,4R,5R)-5-(2,4-dioxo-3,4-dihydropyrimidin-1(2H)-yl)-3,4-dihydroxytetrahydrofuran-2-yl)methyl)-1H-1,2,3-triazol-4-yl)methoxy)-4,5 -dihydroxytetrahydro-2H-pyran-3-yl)acetamide (11e). According to the general procedure, copper(II) sulfate pentahydrate $(3.9 \mathrm{mg}, 0.02 \mathrm{mmol}, 10 \mathrm{~mol} \%)$ and sodium ascorbate $(18.5 \mathrm{mg}$, $0.09 \mathrm{mmol}, 0.6 \mathrm{eq})$ were added to a solution of compound $10(86 \mathrm{mg}, 0.16 \mathrm{mmol}, 1.0 \mathrm{eq})$ and 2-propynyl- $N$-acetyl- $\alpha$-D-glucosamine 6 ( $44.3 \mathrm{mg}, 0.17 \mathrm{mmol}, 1.1 \mathrm{eq})$ with $t \mathrm{BuOH}: \mathrm{H}_{2} \mathrm{O}(10 \mathrm{~mL})$. The reaction mixture was stirred for $5 \mathrm{~h}$ at $40{ }^{\circ} \mathrm{C}$. The reaction was concentrated to dryness in vacuo with co-evaporation of methanol several times. The residue was purified by a flash chromatography (acetone/ $\mathrm{H}_{2} \mathrm{O}$ 9/1) to give the desired product as white solid (97 mg, 77\%). $\mathrm{Rf}$ (acetone/ $\left.\mathrm{H}_{2} \mathrm{O} 9 / 1\right)=0.26$. ${ }^{1} \mathrm{H}-\mathrm{NMR}\left(400 \mathrm{MHz}, \mathrm{DMSO}-\mathrm{d}_{6}\right) \delta(\mathrm{ppm}): 11.35(1 \mathrm{H}, \mathrm{s}, \mathrm{N}-\mathrm{H}) ; 8.04\left(1 \mathrm{H}, \mathrm{s},=\mathrm{CH}_{\text {triazol }}\right) ; 8.00(1 \mathrm{H}, \mathrm{s}$, $\left.=\mathrm{CH}_{\text {triazol }}\right) ; 7.74(1 \mathrm{H}, \mathrm{d}, J=8.21 \mathrm{~Hz}, \mathrm{~N}-\mathrm{H}) ; 7.70(1 \mathrm{H}, \mathrm{d}, J=8.24 \mathrm{~Hz}, \mathrm{~N}-\mathrm{H}) ; 7.59(1 \mathrm{H}, \mathrm{d}, J=8.11 \mathrm{~Hz}$, $=\mathrm{CH}) ; 5.74(1 \mathrm{H}, \mathrm{d}, J=5.37 \mathrm{~Hz}, \mathrm{CH}) ; 5.65(1 \mathrm{H}, \mathrm{d}, J=8.11 \mathrm{~Hz},=\mathrm{CH}) ; 5.53(1 \mathrm{H}, \mathrm{m}, \mathrm{O}-\mathrm{H}) ; 5.49(1 \mathrm{H}, \mathrm{m}$, $\mathrm{O}-\mathrm{H}) ; 5.42(1 \mathrm{H}, \mathrm{m}, \mathrm{O}-\mathrm{H}) ; 4.99(1 \mathrm{H}, \mathrm{m}, \mathrm{O}-\mathrm{H}) ; 4.90(1 \mathrm{H}, \mathrm{m}, \mathrm{O}-\mathrm{H}) ; 4.74(1 \mathrm{H}, \mathrm{d}, J=3.46 \mathrm{~Hz}, \mathrm{CH}) ; 4.72$ $(1 \mathrm{H}, \mathrm{d}, J=3.39 \mathrm{~Hz}, \mathrm{CH}) ; 4.59-4.74(4 \mathrm{H}, \mathrm{m}, 3 \mathrm{CH}) ; 4.46-4.57(3 \mathrm{H}, \mathrm{m}, 3 \mathrm{CH}) ; 4.25-4.35\left(2 \mathrm{H}, \mathrm{m}, \mathrm{CH}_{2}\right)$; 4.10-4.18 (2H, m, 2 CH); $4.09(1 \mathrm{H}, \mathrm{m}, \mathrm{O}-\mathrm{H}) ; 3.98(1 \mathrm{H}, \mathrm{m}, \mathrm{CH}) ; 3.86(1 \mathrm{H}, \mathrm{m}, \mathrm{CH}) ; 3.60-3.70(3 \mathrm{H}, \mathrm{m}$, $3 \mathrm{CH}) ; 3.40-3.53(4 \mathrm{H}, \mathrm{m}, 4 \mathrm{CH}) ; 3.15(1 \mathrm{H}, \mathrm{t}, J=10.28 \mathrm{~Hz}, \mathrm{CH}) ; 3.05(1 \mathrm{H}, \mathrm{t}, J=9.08 \mathrm{~Hz}, \mathrm{CH}) ; 1.80(3 \mathrm{H}, \mathrm{s}$, $\left.\mathrm{CH}_{3}\right) ; 1.76\left(3 \mathrm{H}, \mathrm{s}, \mathrm{CH}_{3}\right) .{ }^{13} \mathrm{C}-\mathrm{NMR}\left(100 \mathrm{MHz}, \mathrm{DMSO}-\mathrm{d}_{6}\right) \delta(\mathrm{ppm}): 169.5,163.0,150.6,143.5,143.4$, 
$141.2,125.1,124.4,102.1,96.4,96.1,88.9,81.8,73.0,72.0,71.9,70.8,70.6,70.5,70.4,70.3,60.8,60.0,59.8$, 53.6, 53.5, 51.4, 50.6, 22.6, 22.5. ESI-HRMS calculated for $\left[\mathrm{C}_{31} \mathrm{H}_{45} \mathrm{~N}_{10} \mathrm{O}_{16}\right]^{+} \mathrm{m} / z 813.3009$ and found $m / z$ 813.3006. IR (neat, $\mathrm{cm}^{-1}$ ): 3306.8br; 2923.4br; 1682.6s; 1548.2m; 1461.6w; 1428.0w; 1378.4w; 1318.5w; $1263.6 w ; 1229.9 w ; 1103.2 m ; 1022.6 s ; 949.6 w ; 841.3 w ; 811.3 w ; 759.8 w .[\alpha]_{\mathrm{D}}{ }^{20}=+113.5(\mathrm{C}=0.01 \mathrm{M}$, $\mathrm{MeOH}) . \mathrm{LC}-\mathrm{MS}$ purity $97.1 \%, \mathrm{t}_{\mathrm{R}}=2.48 \mathrm{~min}$ water/methanol (70:30 vol/vol, $0.1 \%$ of formic acid).

\subsection{Screening of Ligase Inhibitors Using the One-Pot Assay Developed for MurA-F Enzymes of Mycobacterium tuberculosis}

The compounds were prepared in DMSO and screened for inhibitory effect on Mur enzyme activity at a concentration of $100 \mu \mathrm{M}$ using the one pot assay [15]. Briefly, the enzyme mix (MurA-F) was pre-incubated with each inhibitor for $15 \mathrm{~min}$, followed by incubation with UDP- $N$-acetylglucosamine (sugar substrate for MurA). The other reaction components were added as described previously [15] and the reaction mixture was incubated at $37^{\circ} \mathrm{C}$ for $30 \mathrm{~min}$. Release of inorganic phosphate (Pi) was measured at $630 \mathrm{~nm}$ using a PiColorlock ${ }^{\mathrm{TM}}$ Assay kit (Novus Biologicals, New Delhi, India). In the positive control reaction, inhibitor was not added and in the negative control, enzymes were not included and in place of inhibitor, DMSO (5\%) was added. Assays were carried out in 96-wells microtiter plates (Tarsons, New Delhi, India) in triplicates.

After identifying the compounds that showed $50 \%$ or higher inhibition of the one-pot assay, aim was to identify the target Mtb Mur ligases (MurC, MurD, MurE or MurF) for each compound. For this, coupled assay for Mur enzymes was carried out in a sequential manner as described earlier [15]. Briefly, each of the four Mtb Mur ligases was pre-incubated separately with compound for $15 \mathrm{~min}$ and then was added to the total reaction mixture (one at a time) and assayed at $37^{\circ} \mathrm{C}$ for $30 \mathrm{~min}$. The Pi released was calculated as described before. Negative control contained all the components except the Mur ligase enzyme.

\subsection{In Silico Screening}

The compounds showing low $\mathrm{IC}_{50}$ were studied for the stability of binding. Molecular docking of the compounds to the Mtb MurE ligase of Mycobacterium tuberculosis was done using AutoDock Vina [18]. Autodock Vina has significant speed and accuracy and it also allows ligands to be flexible. The 3D structures of identified compounds were prepared using MarvinSketch (ChemAxon Ltd., Budapest, Hungary), whereas, Mtb MurE structure was retrieved from Protein Data Bank (http://www.ecsb/pdb).

\subsection{Protein Structure Preparation}

AutoDock Vina required.pdbqt format of input files. MGLTools software was used to prepare the protein/ligand structures for the docking studies. Structure preparation included (i) removal of water, (ii) addition of hydrogen atoms, (iii) Gasteiger charge addition, (iv) merging of non-polar hydrogen atoms, and energy minimization of the structure. The energy minimization was performed using UCSF Chimera program [19]. Prior to energy minimization, Chimera improves the structural inconsistencies namely, addition of hydrogen and charge to the structure and assigning force field parameters to atoms. The Amber force field parameters were used. Steepest descent minimization was performed followed by conjugate gradient minimization, as it is more effective to reach minimum energy [19].

\subsection{Molecular Dynamic Simulation}

The best fitted confirmations of Mtb MurE and ligand complex were subjected to GROMACS (version 4.5.3) [20] to further examine the stability of interaction between Mtb MurE and ligands. The PRODRG sever [21] was used to generate the ligand topology files. Molecular dynamics (MD) simulation was carried out for 40 ns using GROMOS53a6.ff force field. Initially the system was neutralized with sodium ions followed by energy minimization by using steepest descent method in order to calm down the initial solvent along with abolition of the residual strain. The LINCS algorithm was used to constrain the bond lengths within the protein. The temperature of the system 
was maintained at constant value $300 \mathrm{~K}$ by using Berendsen thermostat and the constant pressure at $1 \mathrm{~atm}$ was sustained by Parrinello-Rahman method.

\subsection{Molecular Docking}

Compounds 11c and 11e were screened against Mtb MurE (PDB ID 2WTZ, [16]) by using an in-house script for the screening of multiple compounds. A rigid docking was performed by constructing the grid with the $40,40,40$ dimension and spacing of $0.375 \AA$. The grid was centered to the active site residues of the Mtb MurE. Binding energy ( $\mathrm{kcal} / \mathrm{mol}$ ) and hydrogen bonds between the compounds and the active site residues in Mtb MurE were considered to study the protein-ligand interactions. Cutoff $(-9.0 \mathrm{kcal} / \mathrm{mol})$ for binding score was referred from a previous report Eniyan et al. [22]. Vina, by default, predicts nine poses for each ligand. The docked complexes were visualized using the Pymol tool [17].

\subsection{Trajectory Analysis}

The g_rms and g_rmsf modules of GROMACS were used to evaluate the root mean square deviation (RMSD) and root mean square fluctuations (RMSF). The RMSD of backbone atoms of the protein was calculated by considering starting coordinates as reference structure. The hydrogen bond interactions were examined by using g_hbond package in GROMACS.

\section{Conclusions}

In summary, we have synthetized various hitherto unknown $5^{\prime}$-deoxy-5'-(4-substituted1,2,3-triazol-1-yl) uridine analogues through CuAAC cross-coupling reactions as the key step with the aim of exploring the structure activity relationships for the inhibition of Mur ligases in Mycobacterium tuberculosis. Out of all the synthesized compounds, the glucosamine uridine derivatives 11c and 11e exhibited an $\mathrm{IC}_{50} \geq 50 \%$ at $100 \mu \mathrm{M}$ on the one-pot assay containing Mycobacterium tuberculosis MurA-F enzymes. Interestingly, we could identify MurE ligase as the potential target for these compounds (11c and 11e showed selective $41.8 \%$ and $48.9 \%$ inhibition, respectively). Altogether, these data indicate that both 11c and 11e are promising selective inhibitors of Mtb MurE ligase and represent starting material for further modifications. Future work will be focused on the chemical optimization of those compounds to more active inhibitors and to allow their penetration [23] in bacterial cells which, even if it remains elusive [24], represents one of the biggest challenges.

Supplementary Materials: ${ }^{1} \mathrm{H}-,{ }^{13} \mathrm{C}$ - and ${ }^{1} \mathrm{H}-{ }^{13} \mathrm{C}$ HMBC NMR spectra of representative molecules $(\mathbf{2}, \mathbf{3 a}-\mathbf{p}, \mathbf{4}$, 6-10, 11a-e) are available online.

Author Contributions: Conceptualization, V.R. and L.A.A.; chemistry of all compounds, V.H.; biological evaluation and inhibition data, R.A., J.R., S.R. and U.B.; writing-original draft preparation, V.R., U.B., L.A.A.; supervision, V.R., U.B. All authors have read and agreed to the published version of the manuscript.

Funding: This work was supported in part by the University of Orleans, CNRS and by LabEx SYNORG (ANR-11-LABX-0029). V.H. thanks LabEx SYNORG for PhD fellowship. We thank Indian Council of Medical Research (ICMR), for Senior Research Fellowship for Jyoti R., University Grant Commission (UGC) for Junior Research Fellowship for Ritu A. and Science and Engineering Research Board (SERB), DST, GoI for research funds. We thank Principal, Acharya Narendra Dev College for the infrastructural support.

Conflicts of Interest: No potential conflict of interest was reported by the authors.

\section{References}

1. Maitra, A.; Munshi, T.; Healy, J.; Martin, L.T.; Vollmer, W.; Keep, N.H.; Bhakta, S. Cell wall peptidoglycan in Mycobacterium tuberculosis: An Achilles' heel for the TB-causing pathogen. FEMS Microbiol. Rev. 2019, 43, 548-575. [CrossRef]

2. Van Heijenoort, J. Recent advances in the formation of the bacterial peptidoglycan monomer unit. Nat. Prod. Rep. 2001, 18, 503-519. [CrossRef] 
3. Barreteau, H.; Kovač, A.; Boniface, A.; Sova, M.; Gobec, S.; Blanot, D. Cytoplasmic steps of peptidoglycan biosynthesis. FEMS Microbiol. Rev. 2008, 32, 168-207. [CrossRef]

4. Jukič, M.; Gobec, S.; Sova, M. Reaching toward underexplored targets in antibacterial drug design. Drug Dev. Res. 2019, 80, 6-10. [CrossRef]

5. Kouidmi, I.; Levesque, R.C.; Paradis-Bleau, C. The biology of Mur ligases as an antibacterial target. Mol. Microbiol. 2014, 94, 242-253. [CrossRef]

6. McKenna, M. Antibiotic resistance: The last resort. Nature 2013, 499, 394-396. [CrossRef]

7. Fernandes, P.; Martens, E. Antibiotics in late clinical development. Biochem. Pharm. 2017, 133, $152-163$. [CrossRef]

8. Hughes, D.; Karlén, A. Discovery and preclinical development of new antibiotics. Upsala J. Med. Sci. 2014, 119, 162-169. [CrossRef]

9. Smith, C.A. Structure, function and dynamics in the mur family of bacterial cell wall ligases. J. Mol. Biol. 2006, 362, 640-655. [CrossRef]

10. Thirumurugan, P.; Matosiuk, D.; Jozwiak, K. Click chemistry for drug development and diverse chemical-biology applications. Chem. Rev. 2013, 113, 4905-4979. [CrossRef]

11. Tornøe, C.W.; Christensen, C.; Meldal, M. Peptidotriazoles on solid phase: $[1,2,3]$-triazoles by regiospecific copper(I)-catalyzed 1,3-dipolar cycloadditions of terminal alkynes to azides. J. Org. Chem. 2002, 67, 3057-3064. [CrossRef]

12. Kolb, H.C.; Finn, M.G.; Sharpless, K.B. Click chemistry: Diverse chemical function from a few good reactions. Angew. Chem. Int. Ed. Engl. 2001, 40, 2004-2021. [CrossRef]

13. Kheng Yeoh, K.; Butters, T.D.; Wilkinson, B.L.; Fairbanks, A.J. Probing replacement of pyrophosphate via click chemistry; synthesis of UPD-sugar analogues as potential glycosyl transferase inhibitors. Carbohydr. Res. 2009, 344, 586-591. [CrossRef]

14. Yamamoto, I.; Sekine, M.; Hata, T. One-step synthesis of 5'-azido-nucleosides. J. Chem. Soc. Perk. Trans. I 1980, 306-310. [CrossRef]

15. Eniyan, K.; Kumar, A.; Vani Rayasam, G.; Perdih, A.; Bajpai, U. Development of a one-pot assay for screening and identification of Mur pathway inhibitors in Mycobacterium tuberculosis. Sci. Rep. 2016, 6, 35134. [CrossRef]

16. Basavannacharya, C.; Robertson, G.; Munshi, T.; Keep, N.H.; Bhakta, S. ATP-dependent MurE ligase in Mycobacterium tuberculosis: Biochemical and structural characterization. Tuberculosis 2010, 90, 16-24. [CrossRef]

17. DeLano, W.L. The PyMOL Molecular Graphics System; Delano Scientific: San Carlos, CA, USA, 2002.

18. Trott, O.; Olson, A.J. AutoDock Vina: Improving the speed and accuracy of docking with a new scoring function, efficient optimization, and multithreading. J. Comput. Chem. 2010, 31, 455-461. [CrossRef]

19. Pettersen, E.F.; Goddard, T.D.; Huang, C.C.; Couch, G.S.; Greenblatt, D.M.; Meng, E.C.; Ferrin, T.E. UCSF Chimera-A visualization system for exploratory research and analysis. J. Comput. Chem. 2004, 25, 1605-1612. [CrossRef]

20. Hess, B.; Kutzner, C.; Spoel, D.V.D.; Lindahl, E. GROMACS 4: Algorithms for Highly Efficient, Load-Balanced, and Scalable Molecular Simulation. J. Chem. Theory Comput. 2008, 4, 435-447. [CrossRef]

21. Schüttelkopf, A.E.; Aalten, D.M.F.V. PRODRG: A tool for high-throughput crystallography of protein-ligand complexes. ACTA Crystallogr. D 2004, 60, 1355-1363. [CrossRef]

22. Eniyan, K.; Rani, J.; Ramachandran, S.; Bhat, R.; Khan, I.A.; Bajpai, U. Screening of Antitubercular Compound Library Identifies Inhibitors of Mur Enzymes in Mycobacterium tuberculosis. SLAS Discov. Adv. Life Sci. R D 2019, 25, 70-78. [CrossRef]

23. Silver, L.L. Novel inhibitors of bacterial cell wall synthesis. Curr. Opin. Microbiol. 2003, 6, 431-438. [CrossRef]

24. Lewis, K. Platforms for antibiotic discovery. Nat. Rev. Drug Discov. 2003, 12, 371-387. [CrossRef]

Sample Availability: All samples of the compounds described are available from the authors.

Publisher's Note: MDPI stays neutral with regard to jurisdictional claims in published maps and institutional affiliations.

(C) 2020 by the authors. Licensee MDPI, Basel, Switzerland. This article is an open access article distributed under the terms and conditions of the Creative Commons Attribution (CC BY) license (http://creativecommons.org/licenses/by/4.0/). 